University of Louisville

ThinkIR: The University of Louisville's Institutional Repository

$5-2021$

\title{
COVID-19 Serological Diagnostic Development Using A SARS- CoV-2 RBD Foldon Fusion
}

Joey Emery Breckenridge Jr.

University of Louisville

Follow this and additional works at: https://ir.library.louisville.edu/etd

Part of the Engineering Commons, and the Medicine and Health Sciences Commons

\section{Recommended Citation}

Breckenridge, Joey Emery Jr., "COVID-19 Serological Diagnostic Development Using A SARS-CoV-2 RBD Foldon Fusion" (2021). Electronic Theses and Dissertations. Paper 3438.

https://doi.org/10.18297/etd/3438

This Master's Thesis is brought to you for free and open access by ThinkIR: The University of Louisville's Institutional Repository. It has been accepted for inclusion in Electronic Theses and Dissertations by an authorized administrator of ThinkIR: The University of Louisville's Institutional Repository. This title appears here courtesy of the author, who has retained all other copyrights. For more information, please contact thinkir@louisville.edu. 


\title{
COVID-19 SEROLOGICAL DIAGNOSTIC DEVELOPMENT USING A SARS-COV-2 RBD FOLDON FUSION
}

By

Joey Breckenridge, Jr.

B.S., University of Louisville, 2020

\author{
A Thesis \\ Submitted to the Faculty of the \\ University of Louisville \\ J. B. Speed School of Engineering \\ as Partial Fulfillment of the Requirements \\ for the Professional Degree
}

MASTER OF ENGINEERING

Department of Bioengineering

April 2021 


\section{COVID-19 SEROLOGICAL DIAGNOSTIC DEVELOPMENT}

USING A SARS-COV-2 RBD FOLDON FUSION

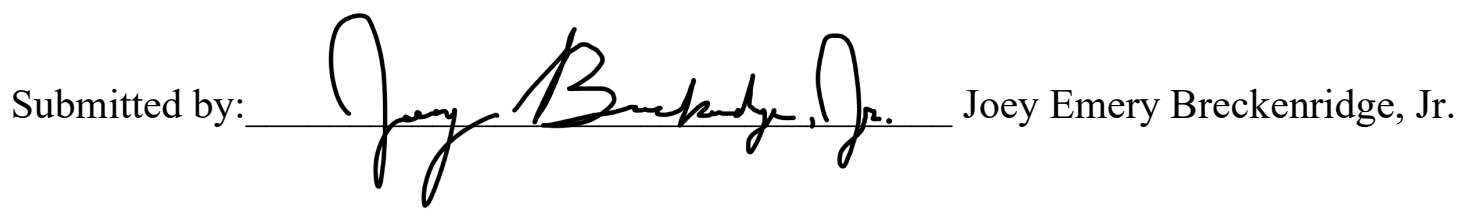

A Thesis Approved on

$4 / 29 / 2021$

(Date)

by the Following Reading and Examination Committee:

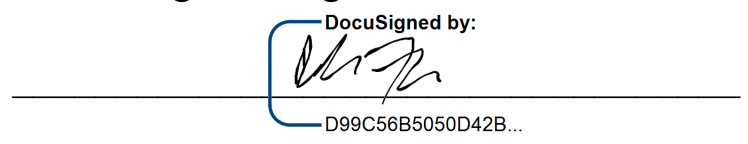

Joshua L. Fuqua, Thesis Director

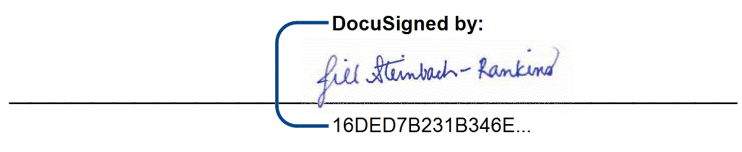

Jill M. Steinbach-Rankins

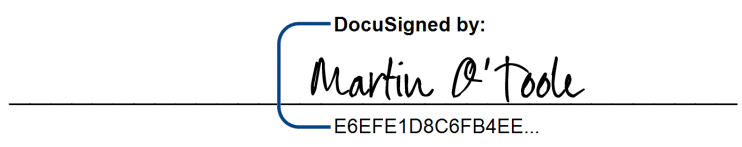

Martin G. O’Toole

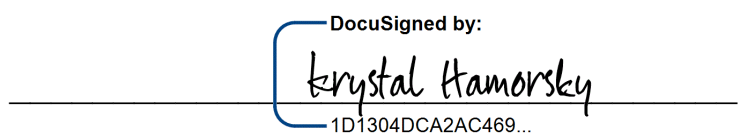

Krystal T. Hamorsky 


\section{ACKNOWLEDGEMENTS}

Firstly, I would like to thank all of the Norton Hospital patients, Co-Immunity participants, and Healthcare Workers whose sera were used in this thesis for donating samples. Secondly, I would like to thank Dr. Joshua Fuqua and Dr. Krystal Hamorsky for giving me their time, insight, and guidance. I would also like to thank Ian Santisteban for assisting me in some of the lab work for this thesis. Lastly, I would like to thank my close family and friends for their support throughout my completion of the Master of Engineering degree. 


\section{TABLE OF CONTENTS}

\section{$\underline{\text { Page }}$}

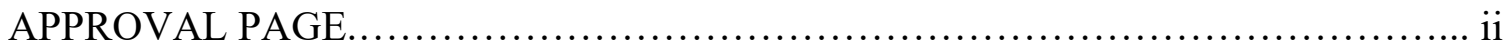

ACKNOWLEDGMENTS ........................................................ ii

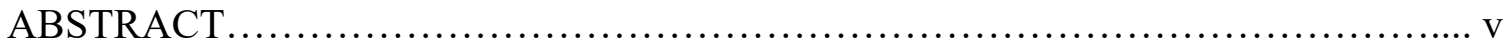

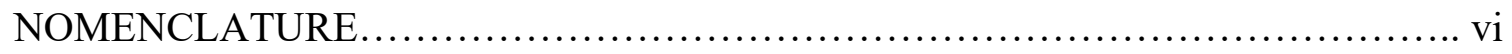

LIST OF TABLES.................................................................. vii

LIST OF FIGURES................................................................ vii

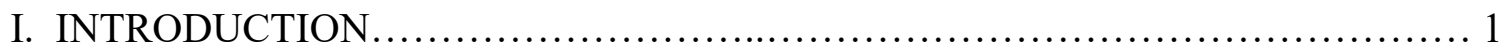

II. INSTRUMENTATION AND EQUIPMENT .................................. 16

III. PROCEDURES.................................................................. 18

IV. RESULTS AND DISCUSSION_........................................... 29

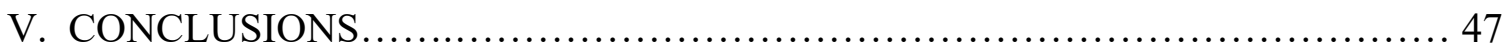

VI. RECOMMENDATIONS .................................................... 49

APPENDIX I. SERA SAMPLE DATA ......................................... 52

APPENDIX II. ROC CURVE DATA ........................................... 57

REFERENCES................................................................ 71

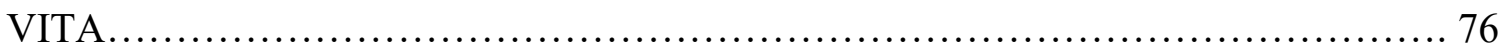




\begin{abstract}
Serological tests are conducted to assess humoral response against viral protein antigens, to assess viral exposure and protection from pathogens. The rapid development and modularity of serological assays have proven critical to managing the current SARSCoV-2 pandemic. The receptor binding domain of SARS-CoV-2 is within the trimeric Spike protein and serves as a highly immunogenic target for potentially neutralizing antibodies. Current receptor binding domain serological assays use recombinant monomers or dimers of the receptor binding domain. The receptor binding domain is presented to the immune system natively in the context of the Spike protein trimer. Therefore, a recombinant trimeric receptor binding domain may be predictive of protection and improve antibody binding. For this thesis, using the trimerization domain from Bacteriophage T4 Fibritin, called Foldon, fused to the receptor binding domain, a novel antigen was produced. The antigen was expressed in and extracted from Nicotiana benthamiana plants, purified through immobilized metal affinity FPLC, and used to develop a serological ELISA. The antigen was tested with hospitalized $(n=46)$, nonhospitalized $(n=36)$, and negative $(n=46)$ patient sera sample lots and batch reproducibility was examined. From these studies, it was concluded that this trimeric antigen can be consistently expressed, extracted, and purified and can be used to reliably detect responses to SARS-CoV-2 in sera. Additionally, fusion of the Foldon trimerization domain to trimeric viral proteins serves as a platform for the development of plant produced viral antigens to better detect host response.
\end{abstract}




\section{NOMENCLATURE}

RBD-foldon $=$ Receptor Binding Domain from Spike Protein S1 Subunit of SARS-CoV2 fused to the C-terminal trimerization domain of bacteriophage T4 fibritin through a glycine-serine linker, called "Foldon", fused to a C-terminal 6x histidine tag.

Spike $=$ The spike protein $(\mathrm{S})$ of SARS-CoV-2, made up of two subunits, S1 and S2 Zoonotic $=$ Descriptor for a pathogen that has jumped from a non-human animal to humans.

ELISA $=$ Enzyme Linked Immuno-Sorbent Assay

TMV $=$ Tobacco Mosaic Virus

FPLC $=$ Fast Protein Liquid Chromatography

HPLC $=$ High Performance Liquid Chromatography

$\mathrm{SEC}=$ Size Exclusion Chromatography

IMAC = Immobilized Metal Affinity Chromatography

$\mathrm{UF} / \mathrm{DF}=$ Ultrafiltration/Diafiltration

PRNT50 = Quantitative value obtained from Plaque Reduction Neutralization Assay; Inverse of the highest sera dilution producing $50 \%$ viral plaque neutralization.

EC50 = Half maximal effective concentration; refers to the binding of a molecule to a receptor. 


\section{LIST OF TABLES}

TABLE I: RBD-foldon Coating Concentration Optical Densities (Row 1) Nearest OD

(Row 2) Cut-off OD at 100\% Specificity ........................................ 36 


\section{LIST OF FIGURES}

FIGURE 1 - SARS-CoV-2 Spike Protein Amino Acid Sequence for Wuhan-Hu-1 Isolate (Purple: Signal Peptide, Green: S1 Subunit, Red: Receptor Binding Domain, Blue: Furin Cleavage Site, Orange: S2 Subunit) ........................................... 7

FIGURE 2 - RBD-foldon ELISA Layout ( $1^{\circ}$ Antibody: Human Sera anti-RBD, $2^{\circ}$ Antibody: Rabbit anti-Human HRP Conjugate, TMB: Reporter Enzyme) .............. 27

FIGURE 3 - Virion Extraction SDS-PAGE [Order from left to right: (1) protein ladder (2) homogenate supernatant post centrifugation (3) miracloth and cheesecloth filtered supernatant (4) post addition of PEG (5) post 2-hour incubation (6) pellet resuspension (7) post 24-hour incubation (8) post centrifugation and miracloth filtration (9) protein ladder]

FIGURE 4 - RBD-foldon Extraction Buffer Panel SDS-PAGE [Order from left to right: (1) protein ladder (2\&3) 50mM Sodium Acetate $\mathrm{pH} 4 \mathrm{w} / \mathrm{o}$ and $w / 200 \mathrm{mM} \mathrm{NaCl}(4 \& 5)$ 50mM Sodium Acetate pH 5 w/o and w/200mM NaCl (6\&7) 50mM Sodium Phosphate pH 6 w/o and w/200mM NaCl (8\&9) 50mM Sodium Phosphate pH 7.5 w/o and w/200mM $\mathrm{NaCl}(10 \& 11) 50 \mathrm{mM}$ Tris $\mathrm{pH} 9 \mathrm{w} / \mathrm{o}$ and $\mathrm{w} / 200 \mathrm{mM} \mathrm{NaCl}$ (12\&13) 50mM Tris $\mathrm{pH} 10 \mathrm{w} / \mathrm{o}$ and $w / 200 \mathrm{mM} \mathrm{NaCl}$ (14) $1 x$ XTMES (15) protein ladder] 
FIGURE 5: RBD-foldon Extraction and Cobalt Affinity Chromatography SDS-PAGE [Order from left to right: (1) protein ladder (2) Miracloth and cheesecloth filtered homogenate (3) Post $1^{\text {st }}$ Centrifugation (4) Post $2^{\text {nd }}$ Centrifugation (5) Post 16 hour $4{ }^{\circ} \mathrm{C}$ incubation (6) Post $3^{\text {rd }}$ Centrifugation (7) Post 0.65 $\mu \mathrm{m}$ Glass Fiber filtration (8) Post $0.2 \mu \mathrm{m}$ bottle-top vacuum filtration (9) IMAC flow through (10) IMAC Wash (11-17) Elution fractions 1A1-1A5, 1B1-1B3 (18) protein ladder] ........................... 32

FIGURE 6: RBD-foldon Ultrafiltration/Diafiltration SDS-PAGE [Order from left to right: (1) protein ladder (2) Load-combined IMAC elution fractions 1A1-1A4 (3) Permeate (4) Retentate (5) protein ladder] .................................... 32

FIGURE 7: RBD-foldon Final Product anti-Histidine Tag Western Blot [Order from left to right: (1) Retentate (2) protein ladder] ................................... 33

FIGURE 8: Lot Variability Batch Purification SDS-PAGE [Order from left to right: (1) protein ladder $(2,6,10,14)$ Lot 5-8 $0.2 \mu$ m filtered homogenate $(3,7,11,15)$ Lot 5-8 Flow through $(4,8,12,16)$ Lot 5-8 Wash $(5,9,13,17)$ Lot 5-8 Eluate (18) protein

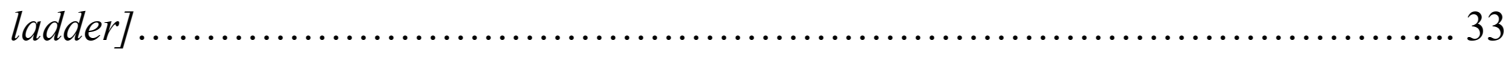

FIGURE 9: Lot Variability UF/DF SDS-PAGE [Order from left to right: (1) protein ladder (2-5) Lot 5-8 Eluate (6-9) Lot 5-8 Permeate (10-13) Lot 5-8 Retentate (14-17) Lot

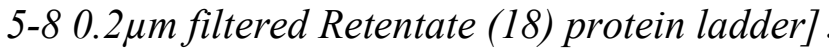
34

FIGURE 10: Mean Percent Difference of Lots 6-8 from Reference Lot Optical Densities

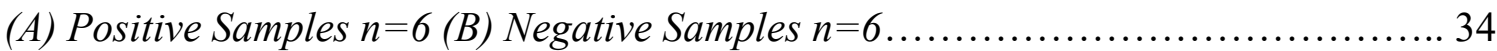


FIGURE 11: ROC Curves for Varying RBD-foldon Coating IgG Responses (positive sample $\mathrm{n}=23$, negative sample $\mathrm{n}=23$ ) (A) $0.5 \mu \mathrm{g} / \mathrm{mL}$ (B) $1 \mu \mathrm{g} / \mathrm{mL}$ (C) $2.5 \mu \mathrm{g} / \mathrm{mL}$ (D)

$5 \mu g / m L$

FIGURE 12: ROC Curves for Patient IgG Response (A) Hospitalized Positive sera $n=46$, Negative sera $n=46$ (B) Non-Hospitalized Positive sera $n=36$, Negative sera $n=46(C)$ All (Hospitalized and Non-Hospitalized) Positive sera $n=82$, Negative sera $n=46$.

FIGURE 13: ROC Curves for Patient IgA and IgM Response (A) IgA Response of all Positive sera $n=82$, Negative sera $n=46$ (B) IgM Response of all Positive sera $n=82$, Negative sera $n=46$.

FIGURE 14: RBD-foldon Hospitalized IgG Titers

FIGURE 15: RBD-foldon Non-Hospitalized IgG Titers

FIGURE 16: RBD-foldon IgG Endpoint Titers vs PRNT50 (A) Hospitalized Positive sera titers $n=46$ vs PRNT50 Values $n=46$ (B) Non-Hospitalized Positive sera titers $n=21$ vs PRNT50 Values $n=21$ 44

FIGURE 17: IgG Endpoint Titer Comparison of RBD-foldon and RBD, $\mathrm{n}=18$ (A) $R B D$ foldon vs RBD Endpoint Titers (B) RBD-foldon Endpoint Titers vs PRNT50 Values (C) RBD Endpoint Titers vs PRNT50 Values.... 


\section{INTRODUCTION}

The first four cases of Coronavirus Disease 2019 (COVID-19) were reported on December 29th of 2019 in Wuhan, China. The symptoms were initially reported as "pneumonia of unknown etiology" (Q. Li et al., 2020). These symptoms were then identified to be a result of a newly identified beta-coronavirus. The World Health Organization initially called this the 2019-novel Coronavirus, and it was later named Severe Acute Respiratory Syndrome Coronavirus 2 (SARS-CoV-2) by the Coronavirus Study Group (CSG) (Guo et al., 2020) as it has significant genetic similarity to Severe Acute Respiratory Syndrome Coronavirus (SARS-CoV) of 2003 (Coronaviridae Study Group of the International Committee on Taxonomy of, 2020). Phylogenetic analysis places SARS-CoV-2 within the family of coronaviridae and genus of beta-coronavirus, sharing phylogenetic similarity to the two other epidemics, beta-coronaviruses SARSCoV and Middle East Respiratory Syndrome (MERS-CoV) (Coronaviridae Study Group of the International Committee on Taxonomy of, 2020). SARS-CoV-2 is more infectious than SARS-CoV and MERS-CoV, and, as of February 27, 2021, there have been over 113 million confirmed cases of and 2.5 million deaths from COVID-19 worldwide (WHO, 2021).

There are four subgroups of coronaviruses: alpha-, beta-, gamma-, and deltacoronaviruses. Alpha- and Beta- coronaviruses infect mammals, while gamma- and deltacoronavirus infect birds. There have been seven human coronaviruses identified: alphacoronaviruses HCoV-229E and -NL63 and beta-coronaviruses HCoV-OC43, -HKU1, SARS-CoV, MERS-CoV, and the most recent SARS-CoV-2 (Chaung, Chan, Pada, \& 
Tambyah, 2020). The HCoV-229E, -NL63, -OC43, and -HKU1 are endemic and are responsible for mild to moderate upper respiratory tract irritation, making up $15-30 \%$ of common cold cases in adults. Contrarily, SARS-CoV, MERS-CoV, and SARS-CoV-2 are zoonotic epidemic pathogens (Chaung et al., 2020).

SARS-CoV-2, ranging from $65-125 \mathrm{~nm}$ in diameter, is a beta-coronavirus, containing positive sense, single-stranded RNA. Its RNA length ranges from 26 to 32 kilobases (Shereen, Khan, Kazmi, Bashir, \& Siddique, 2020). SARS-CoV-2 expresses $\sim 20$ total nonstructural and structural proteins. The four major structural proteins it expresses are: Envelope protein, within the viral membrane; Nucleocapsid protein, within the viral envelope; Spike protein, on the membrane of the viral particle; and Membrane protein, to which the other structural proteins bind and anchor to (Astuti \& Ysrafil, 2020). Spike protein is trimeric, and each monomer is cleaved into subunits S1 and S2, facilitating viral entry into a cell. The Receptor Binding Domain, or RBD, is present within the S1 subunit of Spike protein. RBD (Astuti \& Ysrafil, 2020) is normally presented to the human immune system in the context of the Spike trimer and could provide immunity/protection from SARS-CoV-2 due to its high immunogenicity (Zost et al., 2020). Testing for the immune response to viral exposure is useful in predicting protection and potential vaccine effectiveness over time. However, testing for exposure to and protection from COVID-19 contains a margin of error. This margin of error includes the possibility of false negative and false positive responses as a result of varying assay sensitivities and specificities. Due to the immediate need for testing of exposure and protection as a result of the spike in cases, a number of antigen testing strategies have 
been developed in a short period of time. Although the results of these tests are mostly sufficient, there is a degree of error, and therefore a need to improve them.

Currently, serological diagnostics use SARS-CoV-2 RBD, Spike Protein, or Nucleocapsid protein. Serological diagnostics using SARS-CoV-2 RBD or Spike Protein can predict exposure and protection, whereas those using Nucleocapsid protein can only predict exposure. The most reliable of these serological diagnostics to detect exposure are those using Nucleocapsid or Spike protein as an antigen (Coste, Jaton, PapadimitriouOlivgeris, Greub, \& Croxatto, 2021). Nucleocapsid has a high rate of false positives as it is highly conserved amongst coronaviruses. Spike protein is less conserved and has several glycosylated sites to which more specific antibodies are produced (Meyer, Drosten, \& Muller, 2014). Tests using recombinant non-glycosylated spike protein have an increased level of false negatives (Coste et al., 2021). As for predicting protection, the most reliable of these serological diagnostics are those with RBD as an antigen (Premkumar et al., 2020), but there are still potential false positives and false negatives (Tai, Zhang, He, Jiang, \& Du, 2020). RBD is highly immunogenic and is exposed on the surface of viral particles during binding to the receptor, human Angiotensin Converting Enzyme 2 (hACE2), making it an accessible target for neutralizing antibodies (Zost et al., 2020).

Conversely, Nucleocapsid protein is encapsulated within the viral envelope, and when presented with a viral particle, Nucleocapsid-specific antibodies would not have access to Nucleocapsid protein, being hindered by the viral membrane, and therefore would not be able to exhibit any neutralizing activity. For the scope of this study, 
predicting protection from SARS-CoV-2 is of primary importance. Current serological diagnostics that use RBD as a target antigen use a monomeric or dimeric RBD, while none use a trimeric RBD (Bouwman et al., 2021). Given that RBD is an epitope of the SARS-CoV-2 Spike protein that is presented to the host as a trimer (Yu et al., 2020), a serological test using an RBD that is reflective of that in live virus may correlate better with neutralization than currently used antigens. For this study, a fusion protein was constructed, produced, and characterized. This protein, named "RBD-foldon," fuses the SARS-CoV-2 RBD with the c-terminal trimerization domain of Fibritin from Bacteriophage T4, "Foldon". The development of RBD-foldon will be used as a platform for viral diagnostics and that may be predictive of viral protection.

Aim 1 will establish a reproducible purification method for plant-expressed RBDfoldon. Nicotiana benthamiana plants will be transfected with RBD-foldon viral expression vector to express RBD-foldon through the apoplasts. RBD-foldon protein will then be extracted from transfected plants and purified through IMAC FPLC and concentrated by UF/DF. The final purity of plant-produced RBD-foldon will be verified through SDS PAGE and its identity confirmed with Western Blotting.

Aim 2 will establish a serological assay using RBD-foldon as the target antigen. Serological testing using a plate-based ELISA method allows for the level of immune response to be assessed following an active infection. Plant-produced RBD-foldon in Aim 1 will allow for the optimization of coating concentration of RBD-foldon for ELISAs. Following this, ELISAs will be conducted to assess COVID positive, pre- 
COVID negative, and pre-COVID HIV positive human sera $\mathrm{IgG} / \operatorname{IgA} / \operatorname{IgM}$ responses to RBD-foldon.

Aim 3 will assess the efficacy of RBD-foldon as an antigen for sera immunoglobulins, examining the correlation between immunoglobulin binding of RBDfoldon and viral neutralization. ROC curves will be constructed to assess the sensitivity and specificity of the assay, and antibody titrations will be conducted for each sera sample. The antibody endpoint titers will then be compared to PRNT50 data for each corresponding sera sample to analyze the correlation between the two variables.

The proposed studies will establish a new RBD antigen that will provide better insight into antibody binding of SARS-CoV-2. The innovative antigen will enhance serological assay detection of anti-RBD antibodies and provide a platform for developing new viral antigens to better understand viral function and host immune response.

Research has been conducted and published that provides the basis for developing an RBD antigen that is reflective of the conformation of RBD presented to the human immune system in a SARS-CoV-2 infection.

The complete genome of SARS-CoV-2 was first sequenced by Lu, Zhao, et al. They obtained samples from nine inpatients with viral pneumonia, eight of which had been to the market in the period in which the outbreak may have originated in Wuhan, China, the ninth having stayed in a hotel near the market. Each patient tested negative for all common respiratory pathogens. Eight complete genome and two partial genome sequences of SARS-CoV-2 were obtained from the nine samples. Lu, Zhao, et al. compared sequence homology between the SARS-CoV-2 sequence, two SARS-like bat 
coronavirus (BatCoV-ZC45 and BatCoV-ZXC21), SARS-CoV, and MERS-CoV. The SARS-CoV-2 sequence shared $88 \%$ sequence homology with both SARS-like bat coronaviruses, suggesting that bats may have been the intermediate that enabled the virus to transition from animals to infecting humans (Lu et al., 2020). The sequence homology with SARS-CoV and MERS-CoV were 79\% and 50\% respectively. When comparing the predicted coding regions of each known coronavirus sequence to those of SARS-CoV-2, $\mathrm{Lu}$, Zhao, et al. found that SARS-CoV-2 had a comparable genomic organization to BatCoV-ZC45, BatCoV-ZXC21, and SARS-CoV. They also found that, except for minor insertions or deletions, the lengths of most of the encoded proteins were similar. Another study by Zhou et al. found that SARS-CoV-2 showed high genome sequence homology to BatCoV-RaTG13 of $96.2 \%$, suggesting that BatCoV-RaTG13 is the closest relative to SARS-CoV-2 (Zhou et al., 2020a, 2020b).

The spike protein $(\mathrm{S})$ of coronaviruses cleaves into two subunits: an S1 domain, containing a receptor binding domain $(\mathrm{RBD})$, and an $\mathrm{S} 2$ domain, which is responsible for membrane fusion (Figure 1). After examining the amino acid sequence of the $\mathrm{S}$ domain, SARS-CoV-2 was determined to have 50 conserved amino acids in S1 with SARS-CoV (Lu et al., 2020). This homology suggests a similar receptor binding mechanism between SARS-CoV and SARS-CoV-2. Complementarily, in a study conducted by Tang, et al., it was determined the fusion protein (FP) in the S2 domain of SARS-CoV-2 has 93\% sequence homology with that of SARS-CoV, suggesting a similar membrane fusion mechanism between the two coronaviruses (Tang, Bidon, Jaimes, Whittaker, \& Daniel, 2020). In the same study, Tang et al. also state that within the S1 subunit of coronavirus 
spike protein are two subdomains which can both serve as the Receptor Binding Domain (RBD), interacting directly with the receptor. These subdomains are called the N-terminal domain (NTD) and the C-terminal domain (CTD) (Tang et al., 2020). The CTD serves as the Receptor Binding Domain in SARS-CoV-2, SARS-CoV, and MERS-CoV(Peng et al., 2011; Tang et al., 2020; Zost et al., 2020). The CTD of both SARS-CoV and SARS-CoV2 bind to angiotensin converting enzyme 2 (ACE2), while the CTD of MERS-CoV binds to dipeptidyl peptidase 4 (DPP4). Determined by Peng et al., the NTD facilitates binding of sugar-receptors, whereas the CTD facilitates binding of protein-type receptors (Peng et al., 2011); hence, the CTD binding with the protein-type receptors ACE2 and DPP4.

\footnotetext{
1 MFVFLVLLPLVSSQCVNLTTRTQLPPAYTNSFTRGVYYPDKVFRSSVLHSTQDLFLPFFSNVTWFHAIHVSGTNGTKRFDNPVLPFNDGV 91 YFASTEKSNIIRGWIFGTTLDSKTQSLLIVNNATNVVIKVCEFQFCNDPFLGVYYHKNNKSWMESEFRVYSSANNCTFEYVSQPFLMDLE 181 GKQGNFKNLREFVFKNIDGYFKIYSKHTPINLVRDLPQGFSALEPLVDLPIGINITRFQTLLALHRSYLTPGDSSSGWTAGAAAYYVGYL 271 QPRTFLLKYNENGTITDAVDCALDPLSETKCTLKSFTVEKGIYQTSNFRVQPTESIVRFPNITNLCPFGEVFNATRFASVYAWNRKRISN 361 CVADYSVLYNSASFSTFKCYGVSPTKLNDLCFTNVYADSFVIRGDEVRQIAPGQTGKIADYNYKLPDDFTGCVIAWNSNNLDSKVGGNYN 451 YLYRLFRKSNLKPFERDISTEIYQAGSTPCNGVEGFNCYFPLQSYGFQPTNGVGYQPYRVVVLSFELLHAPATVCGPKKSTNLVKNKCVN 541 FNFNGLTGTGVLTESNKKFLPFQQFGRDIADTTDAVRDPQTLEILDITPCSFGGVSVITPGTNTSNQVAVLYQDVNCTEVPVAIHADQLT 631 PTWRVYSTGSNVFQTRAGCLIGAEHVNNSYECDIPIGAGICASYQTQTNSPRRARSVASQSIIAYTMSLGAENSVAYSNNSIAIPTNFTI 721 SVTTEILPVSMTKTSVDCTMYICGDSTECSNLLLQYGSFCTQLNRALTGIAVEQDKNTQEVFAQVKQIYKTPPIKDFGGFNFSQILPDPS 811 KPSKRSFIEDLLFNKVTLADAGFIKQYGDCLGDIAARDLICAQKFNGLTVLPPLLTDEMIAQYTSALLAGTITSGWTFGAGAALQIPFAM 901 QMAYRFNGIGVTQNVLYENQKLIANQFNSAIGKIQDSLSSTASALGKLQDVVNQNAQALNTLVKQLSSNFGAISSVLNDILSRLDKVEAE 991 VQIDRLITGRLQSLQTYVTQQLIRAAEIRASANLAATKMSECVLGQSKRVDFCGKGYHLMSFPQSAPHGVVFLHVTYVPAQEKNFTTAPA 1081 ICHDGKAHFPREGVFVSNGTHWFVTQRNFYEPQIITTDNTFVSGNCDVVIGIVNNTVYDPLQPELDSFKEELDKYFKNHTSPDVDLGDIS 1171 GINASVVNIQKEIDRLNEVAKNLNESLIDLQELGKYEQYIKWPWYIWLGFIAGLIAIVMVTIMLCCMTSCCSCLKGCCSCGSCCKFDEDD 1261 SEPVLKGVKLHYT
}

FIGURE 1 - SARS-CoV-2 Spike Protein Amino Acid Sequence for Wuhan-Hu-1 Isolate (Purple: Signal Peptide, Green: S1 Subunit, Red: Receptor Binding Domain, Blue: Furin Cleavage Site, Orange: S2 Subunit)

In a study conducted by Yan et al., they investigated the structural basis for the recognition of SARS-CoV-2 by human ACE2 (Yan et al., 2020). ACE2 is prevalent in humans in the lung and intestine epithelium, and less prevalent throughout the venous 
and arterial endothelium and arterial muscle cells throughout the body (Hamming et al., 2004). ACE2 is responsible for mediating the maturation of the peptide hormone angiotensin, which is the end product in the renin-angiotensin system of the kidney, responsible for mediating blood pressure through vasoconstriction of blood vessels throughout the body (Yan et al., 2020). ACE2 is a functional dimer consisting of an Nterminal peptidase domain and a c-terminal collectrin domain. The peptidase domain is a carboxypeptidase (cleaves one c-terminal peptide) and is responsible for cleavage of Angiotensin I into angiotensin-(1-9) and of octapeptide angiotensin-(1-8) into angiotensin-(1-7) (Huang, Yang, Xu, Xu, \& Liu, 2020; Kowalczuk et al., 2008). The peptidase cleavage mechanism gives ACE2 an open and closed conformation. The collectrin domain is a transmembrane protein that anchors ACE2 to the plasma membrane (Zhang et al., 2007). It also contains the domains responsible for dimerization of ACE2 and is the chaperone for broad neutral amino acid transporter 1, known as $\mathrm{B}^{0} \mathrm{AT} 1$, which is responsible for neutral amino acid uptake in intestinal cells (Bader, Turner, \& Alenina, 2020; Kowalczuk et al., 2008; Yan et al., 2020). Yan et al. determined that the structure of ACE2 is revealed in the presence of $\mathrm{B}^{0} \mathrm{AT} 1$, forming an ACE2-B ${ }^{0}$ AT1 complex, which was determined by cryo-electron microscopy (cryo-EM) to be a dimer of heterodimers. They also revealed that the RBD of SARS-CoV-2 recognizes and binds to the peptidase domain of ACE2. Using structural alignment of the RBD-ACE2-B ${ }^{0}$ AT1 complex with the SARS-CoV-2 spike protein, they hypothesized that each ACE2-B ${ }^{0} \mathrm{AT} 1$ complex could bind two spike protein trimers simultaneously. Using cryo-EM, a 3D electron microscopy reconstruction of the RBD-ACE2-B ${ }^{0} \mathrm{AT} 1$ 
complex was obtained, showing each peptidase domain bound to one RBD each, confirming their hypothesis was correct. Additionally, the closed state of ACE2 was observed in the RBD-ACE2-B ${ }^{0}$ AT1 complex (Yan et al., 2020).

Tai et al. conducted a study in which they reported that SARS-CoV-2 RBD binds strongly to human ACE2 receptors (Tai, He, et al., 2020). They identified the RBD containing portion of SARS-CoV-2 spike protein and using flow cytometry, found recombinant SARS-CoV-2 RBD protein bound to ACE2 receptors. Additionally, when the recombinant RBD is bound to ACE2, it prevented SARS-CoV-2 entry into ACE2 expressing cells (Tai, He, et al., 2020). They conclude that RBD could serve as a viral attachment inhibitor against SARS-CoV-2 infection; however, this would not be an effective treatment as ACE2 is conformationally locked when in complex with RBD, and would not be able to function properly, causing pathophysiological effects (Bader et al., 2020; Yan et al., 2020). Tai et al. also compared the binding affinity of SARS-CoV-2 RBD to ACE2 with that of SARS-CoV RBD and MERS-CoV RBD. They found that SARS-CoV-2 RBD bound with much stronger affinity to ACE2 than SARS-CoV RBD, shown by EC50 values of $0.14 \pm 0.05 \mu \mathrm{g} / \mathrm{mL}$ and $1.32 \pm 0.09 \mu \mathrm{g} / \mathrm{mL}$, respectively. MERSCoV RBD did not bind ACE2 since it uses the DPP4 receptor for cell entry (Tai, He, et al., 2020).

Similarly, the binding motif of RBD to ACE2 was reported by Wang et al. (Wang et al., 2020). From previously published literature on SARS-CoV, the CTD of SARSCoV RBD was known to bind to ACE2, and that SARS-CoV-2 RBD behaved similarly. However, binding of SARS-CoV-2 RBD to ACE2 through the CTD had not been directly 
tested. They showed that SARS-CoV-2 RBD CTD had high affinity for ACE2 using flow cytometry. Following this, to form the SARS-CoV-2 RBD CTD-ACE2 complex, an in vitro mixture of SARS-CoV-2 RBD CTD and ACE2 was prepared. The complex was isolated using Size Exclusion Chromatography (SEC). The crystal structure of the complex was then determined, enabling Wang et al. to confirm that the CTD of SARSCoV-2 RBD definitively binds to ACE2 (Wang et al., 2020).

Huang et al. detail the structural and functional properties of the spike protein of SARS-CoV-2, revealing the behavior of RBD during attachment to ACE2. They note that the spike protein RBD domain has an "up" and "down" conformation, as previously determined through cryo-EM by Wrapp et al. and Walls et al.(Walls et al., 2020; Wrapp et al., 2020). RBD is in the "down" conformation when spike is not interacting with a host receptor and is referred to by Wrapp et al. as the prefusion conformation of the spike protein trimer. The prefusion trimer gets destabilized when the RBD (within S1) shifts to the "open" conformation to bind to ACE2.

It is important to note that the Spike protein is highly immunogenic, and therefore would be the target for neutralizing antibodies (Walls et al., 2020). In a review by $\mathrm{Yu}$, Xiang, et al., they report that after SARS-CoV-2 RBD was screened with neutralizing monoclonal antibodies, it was revealed that it consisted of a number of neutralizing epitopes (Yu et al., 2020). In a study conducted by Zost et al., they analyzed a panel $(n=389)$ of human monoclonal antibodies to SARS-CoV-2 spike protein. They found a significant number of them that exhibited neutralizing activity and also block RBD interaction with ACE2 (Zost et al., 2020). Considering the immunogenicity of RBD and 
the RBD binding mechanism with ACE2, RBD of SARS-CoV-2 is a primary target for neutralizing antibodies and can elicit a strong host adaptive immune response.

During an active infection, SARS-CoV-2 RNA and proteins are detectable in multiple bodily fluids, including saliva, tears, and feces (Kutti-Sridharan, Vegunta, Vegunta, Mohan, \& Rokkam, 2020). Post-infection of SARS-CoV-2, seroconversion occurs, at which point the host adaptive immune system antibody production reaches peak levels. Long et al. conducted a study in which they observed antibody responses to SARS-CoV-2 in 285 COVID-19 patients (Long et al., 2020). Seroconversion of IgG or IgM occurred within 20 days after onset of symptoms before plateau. SARS-CoV-2 is detected using molecular assays, while the humoral response to SARS-CoV-2 is detected using serological assays. In a review by Younes et al., they discuss that the gold standard for detecting an active SARS-CoV-2 infection is using a molecular-based assay called quantitative real-time reverse transcriptase PCR, qRT-PCR (Toptan et al., 2020; Younes et al., 2020). qRT-PCR allows for the quantification of viral RNA by detecting the complementary DNA (cDNA). RNA gets reverse transcribed into cDNA, which is detected once enough replication cycles have been completed, achieving a detectable signal (Bustin \& Mueller, 2005). The PCR quantitative output is fluorescence. Fluorescence occurs when a PCR product is amplified. A significant fluorescence increase is detected at a time inversely proportional to the copy number of the starting nucleic acid target (Bustin \& Mueller, 2005).

While qRT-PCR detects the genetic material of SARS-CoV-2 and is useful for diagnosing active SARS-CoV-2 infection, it cannot diagnose previous exposure to 
SARS-CoV-2. Determining if a given person has had a previous infection is important in tracing SARS-CoV-2 exposure throughout the population and assessing potential host immunity. Humoral response and previous SARS-CoV-2 exposure are determined using serological testing. Serological assays detect antibodies from patient plasma or serum that target SARS-CoV-2 immunogenic proteins(Lee, Lin, Renia, \& Ng, 2020). There are three types of serological tests commercially used for SARS-CoV-2: Enzyme Immunoassays (Chemiluminescence Enzyme Immunoassays [CLIA] and Enzyme Linked ImmunoSorbent Assays [ELISA]) and Lateral Flow Immunoassays (LFIA) (Nicol et al., 2020; Younes et al., 2020). LFIA is similar to home pregnancy tests and personal blood glucose monitors for diabetes, in which a fluid analyte (i.e. blood, saliva, urine) flows across zones of polymeric strips. Antibodies that are specific for a target antigen within the analyte are bound to the polymeric strips. LFIA also is a rapid test that returns results within 5-30 minutes (Koczula \& Gallotta, 2016). Enzyme immunoassays for SARS-CoV2 use a target antigen that binds to the well of a microplate (commonly 96-well plate), to which antibodies in human sera or plasma bind. The primary $\left(1^{\circ}\right)$ antibodies bound to the target immunogen are then bound by a secondary $\left(2^{\circ}\right)$ antibody that is not reactive to the target immunogen. The target immunogen $-1^{\circ}$ antibody- $2^{\circ}$ antibody complex is then detected. For CLIA, the $2^{\circ}$ antibody is labeled with isoluminol, which is activated to luminesce with an oxidant (i.e. hydrogen peroxide), allowing the amount of $1^{\circ}$ antibody bound to be measured with reference to the luminescence emitted (Cinquanta, Fontana, \& Bizzaro, 2017). For ELISA, the $2^{\circ}$ antibody is conjugated to horseradish peroxidase (HRP) or alkaline phosphatase (ALP), which is then detected with substrate solution, 
allowing for the amount of $1^{\circ}$ antibody bound to be measured with reference to the Optical Density (OD) of the well. As earlier mentioned, in addition to Spike protein, SARS-CoV-2 also consists of three other main structural proteins: Envelope protein, Membrane Protein, and Nucleocapsid Protein. Of these structural proteins, Nucleocapsid and Spike protein (including RBD) are used in SARS-CoV-2 serological assays, as Nucleocapsid protein is amply expressed during infection and Spike protein is highly exposed.

In a study published in 2004 , by Sun et al., they examined antigenic crossreactivity between the Nucleocapsid protein of SARS-CoV and other known coronaviruses, and they concluded that the SARS-CoV nucleocapsid protein was responsible for antigenic cross-reactivity with sera positive for other coronaviruses, noting that nucleocapsid protein is the most conserved protein between coronaviruses (Sun \& Meng, 2004). In a similar study published in 2021 by Tso et al., it was shown that SARS-CoV-2 nucleocapsid protein was cross-reactive with known endemic coronaviruses (Tso et al., 2021). As nucleocapsid protein is the most conserved protein among coronaviruses, humoral responses to nucleocapsid protein are not highly specific to SARS-CoV-2 as antibodies are cross-reactive with nucleocapsid from various other endemic viruses (i.e. HCoV-229E, -NL63, -OC43, -HKU1), resulting in false positive results and decreased assay specificity (Younes et al., 2020).

As previously mentioned, in serological assays for SARS-CoV-2, recombinant nucleocapsid, spike protein, and receptor binding domain have been used. Since it is not a trimer in native form, to allow for trimerization of recombinant receptor binding domains, 
a trimerization domain would need to be used. Foldon is the C-terminal domain of the bacteriophage T4 head, Fibritin. Fibritin is a trimeric protein that has a 486 amino acid sequence and has chaperone, sensory, and structural properties (Meier, Guthe, Kiefhaber, \& Grzesiek, 2004). Foldon is critical for the trimerization of fibritin (Letarov, Londer, Boudko, \& Mesyanzhinov, 1999; Meier et al., 2004). Several studies investigating the production of trimeric recombinant proteins have been conducted that demonstrate that foldon can be used as a stable trimerization domain (i.e., fusion with influenza hemagglutinin or rabies virus glycoprotein) (Chen et al., 2010; Frank et al., 2001; Papanikolopoulou, Forge, Goeltz, \& Mitraki, 2004; Sissoeff, Mousli, England, \& Tuffereau, 2005; Welsh, Lu, He, Greenberg, \& Swartz, 2012). Specifically, for coronaviruses, this was demonstrated in a study conducted by Tai et al., in which they fused foldon to the RBD of MERS-CoV (Tai et al., 2016). In the study, they fused foldon to the c-terminus of MERS-CoV RBD, along with a $6 \mathrm{X}$-histidine tag to allow for affinity purification of the trimeric RBD. They then characterized the protein, determining its antigenicity, receptor binding affinity, immunogenicity, neutralization potential, and efficacy in protecting human DPP4-transgenic mice in a MERS-CoV challenge. They ran neutralization assays on immunized mice sera to assess antigenicity and neutralization potential. They found that the MERS-CoV RBD foldon fusion successfully protected mice from infection and elicited strong MERS-CoV RBD specific neutralizing antibody responses. Li et al. conducted a similar study, in which they fused foldon to the cterminus of SARS-CoV S1 subunit and S protein along with a $9 \mathrm{X}$ histidine tag for affinity purification, assessing their immunogenicity and efficacy in protecting mice from 
a SARS-CoV challenge(J. Li, Ulitzky, Silberstein, Taylor, \& Viscidi, 2013). They compared foldon fused SARS-CoV S1 and Spike protein to monomeric SARS-CoV S1 and Spike protein. They found that each protein (monomeric Spike and S1, trimeric foldon fused Spike and S1) successfully protected mice from infection and that the SARS-CoV spike foldon fusion elicited the highest level of neutralizing antibodies compared to the other constructs they tested.

Due to Spike protein's structural and functional similarity between coronaviruses, these studies provide insight that suggests the potential efficacy of a SARS-CoV-2 RBDfoldon fusion as an antigen in a diagnostic assay (Lu et al., 2020; Sivaraman, Er, Choong, Gavor, \& Sivaraman, 2021). 


\section{INSTRUMENTATION AND EQUIPMENT}

For the assays and experiments detailed in section III, the following materials were used:

Bio-rad Criterion ${ }^{\mathrm{TM}}$ Electrophoresis Cell

Criterion $^{\mathrm{TM}}$ XT $12 \%$ Bis-Tris pre-cast gels

Bio-rad 1X XT-MES running buffer

GE Amersham ${ }^{\mathrm{TM}}$ Imager 600

Bio-rad Trans-Blot ${ }^{\circledR}$ Turbo $^{\mathrm{TM}}$ Transfer System

Thermo Scientific ${ }^{\mathrm{TM}} \mathrm{MaxQ}^{\mathrm{TM}} 2000$ Orbital Shaker

GE Amersham ${ }^{\mathrm{TM}}$ ECL $^{\mathrm{TM}}$ Prime Western Blotting Detection Reagent

New England Biotech Stable Competent E. Coli cells

OMEGA Bio-tek E.Z.N.A Plasmid DNA Midi Prep Kit

Invitrogen mMESSAGE mMACHINE ${ }^{\mathrm{TM}} \mathrm{T} 7 \mathrm{Kit}$

Precellys ${ }^{\circledR} 24$ Tissue Homogenizer

Thermo Scientific ${ }^{\mathrm{TM}}$ Sorvall Legend XTR Centrifuge

Sartorius Stedim Biotech SartoScale $0.65 \mu \mathrm{m}$ Disposable Filters

Thermo Scientific ${ }^{\mathrm{TM}}$ Nalgene ${ }^{\mathrm{TM}}$ Rapid-Flow $^{\mathrm{TM}}$ Sterile Single Use $0.2 \mu \mathrm{m}$ Filter

GE ÄKTA Pure Chromatography System

GE TALON® Superflow ${ }^{\mathrm{TM}}$ Resin

Intermountain Life Sciences 1x Phosphate-Buffered Saline without Calcium and Magnesium

Millipore Amicon ${ }^{\circledR}$ Ultra-15 Ultracel ${ }^{\circledR}$ Regenerated Cellulose 10000 Molecular Weight Cut-Off/Nominal Molecular Weight Limit (MWCO/NMWL) Centrifugal Filters 
Thermo Scientific ${ }^{\mathrm{TM}}$ Heraeus Multifuge X3R Centrifuge

PALL Life Sciences Nanosep with $0.2 \mu \mathrm{m}$ wwPTFE

Thermo Fisher Nanodrop ${ }^{\mathrm{TM}} 1000$

Thermo Scientific 96-well microplates

Eppendorf Xplorer 50-1200 $\mu$ L Multichannel Repeater Pipette

BioTek® EL406 Plate Washer

Thermo Scientific Pierce ${ }^{\mathrm{TM}}$ Protein-Free PBS Blocking Buffer

Thermo Scientific 1-Step ${ }^{\mathrm{TM}}$ Ultra TMB-ELISA

BioTek ${ }^{\circledR}$ Synergy ${ }^{\mathrm{TM}}$ HT Plate Reader 


\section{PROCEDURES}

\section{A. Plasmid Design}

To construct RBD-foldon, the Foldon DNA sequence was added to the 3' end of the RBD DNA sequence using a Glycine-Serine (GGGGS) linker, along with the DNA sequence encoding a C-terminal 6x histidine tag. A signal peptide (BPT1_BOVIN Pancreatic Trypsin Inhibitor) was also added to the 5' end of the RBD DNA sequence. The full sequence with parenthesis to indicate differing proteins was as follows: (MKMSRLCLSVALLVLLGTLAA)(RVQPTESIVRFPNITNLCPFGEVFNATRFASVY AWNRKRISNCVADYSVLYNSASFSTFKCYGVSPTKLNDLCFTNVYADSFVIRGD EVRQIAPGQTGKIADYNYKLPDDFTGCVIAWNSNNLDSKVGGNYNYLYRLFRKS NLKPFERDISTEIYQAGSTPCNGVEGFNCYFPLQSYGFQPTNGVGYQPYRVVVLS FELLHAPATVCGPKKSTNLVKNKCVNF)(GGGGS)(YIPEAPRDGQAYVRKDGEW VLLSTFLG)(HHHHHH). This fused sequence was inserted in a Geneware ${ }^{\circledR}$ plasmid expression vector. The Geneware ${ }^{\circledR}$ vector includes DNA encoding tobacco mosaic virus, enabling protein expression in Nicotiana benthamiana plants. The plasmid was assembled for bacterial expression by ATUM (Newark, CA).

\section{B. Sodium Dodecyl Sulfate Polyacrylamide Gel Electrophoresis (SDS-PAGE)}

SDS-PAGE samples were prepared using three volumes of protein sample and one volume $4 \mathrm{X}$ SDS loading dye. SDS loading dye (4X) was made with $6.25 \mathrm{~mL}$ of $1 \mathrm{M}$

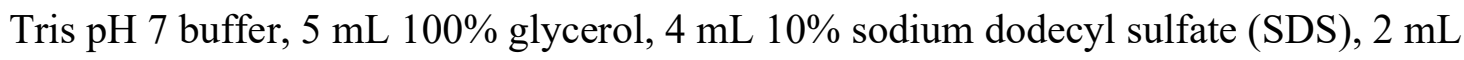
$\beta$-mercaptoethanol (BME), $7.75 \mathrm{~mL}$ de-ionized water, and $10 \mathrm{mg}$ bromophenol blue. Bio- 
rad Criterion ${ }^{\mathrm{TM}}$ Electrophoresis Cells and Criterion ${ }^{\mathrm{TM}} \mathrm{XT} 12 \%$ Bis-Tris pre-cast gels were used. Gels were ran using 1X XT-MES running buffer (Bio-rad) at 200V for 45 minutes. Stain solution was made using $2 \mathrm{~g}$ of Coomassie Blue R-250, $200 \mathrm{~mL}$ acetic

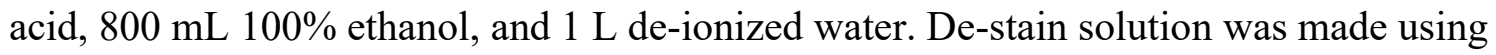
1.65 L de-ionized water, $150 \mathrm{~mL}$ acetic acid, and $200 \mathrm{~mL} \mathrm{100 \%} \mathrm{ethanol.} \mathrm{Following}$ staining and de-staining, images were taken using colorimetric transillumination (GE Amersham $^{\mathrm{TM}}$ Imager 600).

\section{Western Blotting}

First, SDS-PAGE was run. The gel was not stained, and the gel contents were transferred to a PVDF membrane using a Western Blot transfer kit (Bio-rad Trans-Blot ${ }^{\circledR}$ Turbo $^{\mathrm{TM}}$ Transfer System). Powdered milk was resolubilized in $50 \mathrm{~mL}$ of $1 \mathrm{x}$ phosphatebuffered saline tween-20 (PBST) solution to make a 3\% w/v solution. $20 \mathrm{~mL}$ of 3\% PBST-milk was then used to make $60 \mathrm{~mL}$ of 1\% PBST-milk. Mouse anti Histidine Primary antibody (GenScript Catalog No. A00186-100) was diluted 1:3,000. Goat anti Mouse Secondary antibody (Southern Biotech Catalog No. 1030-05) was diluted 1:6,000. Primary and secondary antibody dilutions were each made in $30 \mathrm{~mL}$ of $1 \%$ PBST-milk. All wash steps were done three times with 1x PBST solution. The membrane was manually washed, then placed in $30 \mathrm{~mL}$ of 3\% PBST-milk and incubated on an orbital shaker at 100 RPM for $12-16$ hours at $4^{\circ} \mathrm{C}$. The membrane was then washed, placed in 30 $\mathrm{mL}$ primary antibody solution, and placed on an orbital shaker at $100 \mathrm{RPM}$ for 1 hours at room temperature. Following this, the membrane was washed, placed in $30 \mathrm{~mL}$ secondary antibody solution, and placed on an orbital shaker at 100 RPM for 1 hours at 
room temperature. The membrane was washed a final time, then $1 \mathrm{~mL}$ of development solution was washed over the membrane. Development solution was made with $0.5 \mathrm{~mL}$ hydrogen peroxide and $0.5 \mathrm{~mL}$ luminol (GE Amersham ${ }^{\mathrm{TM}} \mathrm{ECL}^{\mathrm{TM}}$ Prime Western Blotting Detection Reagent). Images were taken using epifluorescence (GE Amersham ${ }^{\mathrm{TM}}$ Imager 600).

\section{Plasmid Amplification and Virion Extraction}

The plasmid was transformed in E. coli bacteria (New England Biotech Stable Competent $E$. coli cells). The bacteria were lysed, and the recombinant DNA was isolated (OMEGA Bio-tek E.Z.N.A Plasmid DNA Midi Prep Kit). Prepped DNA was then transcribed to RNA (Invitrogen mMESSAGE mMACHINE ${ }^{\mathrm{TM}} \mathrm{T} 7 \mathrm{Kit}$ ). The transcription reaction was verified through DNA gel electrophoresis with Ethidium Bromide (Bio-Rad) used as an intercalating agent. For Nicotiana benthamiana inoculation, transcribed RNA was mixed with plant inoculation buffer (60mM Glycine, 36mM Potassium Phosphate Dibasic Trihydrate, 13mM Sodium Pyrophosphate Decahydrate, 55mM Bentonite, and $94 \mathrm{mM}$ Celite) to a concentration of $0.5 \mathrm{ng} / \mu \mathrm{L}$. This mixture was used to inoculate leaves 4 and 5 of 28-35 days post sow Nicotiana benthamiana plants. Plants were harvested 5 days post inoculation and virion was extracted to verify TMV expression. Virion was extracted by PEG Precipitation (Corman et al., 2020). Virion PEG precipitation samples were run on SDS PAGE to verify virion had been isolated. The concentration of virion was determined from the absorbance at a wavelength of $260 \mathrm{~nm}$ (Thermo Fisher NanodropTM 1000). Virion was aliquoted and stored at $-20^{\circ} \mathrm{C}$ to be used to inoculate additional plants to produce RBD-foldon protein. 


\section{E. RBD-foldon Nicotiana benthamiana Infiltration}

Nicotiana benthamiana plants were grown to 28-35 days post sow, then infiltrated with $100 \mu \mathrm{L}$ of $0.5 \mathrm{ng} / \mu \mathrm{L}$ virion, using plant inoculation buffer to allow virion entrance into plants. Whole plants were harvested at 14 Days Post-Infiltration and harvested tissue was stored at $-20^{\circ} \mathrm{C}$.

\section{F. RBD-foldon Extraction Buffer Panel}

A panel of buffers was used to determine ideal buffer conditions for extraction of RBD-foldon. Twelve buffers were tested: Sodium Acetate $\mathrm{pH} 4$ and 5, Sodium Phosphate pH 6 and 7.5, Tris pH 9 and 10, each with and without 200 mM Sodium Chloride. All buffers were made at $50 \mathrm{mM}$ concentration with $10 \mathrm{mM}$ Sodium Metabisulfite and 20 mM Ascorbic Acid. For each buffer, 0.5 grams of RBD-foldon infected plant tissue was homogenized at a 1:1 w/v ratio. A Precellys 24 Tissue Homogenizer was used at 6500RPM. Samples were taken at each step and analyzed with SDS-PAGE.

\section{G. RBD-foldon Extraction}

RBD-foldon protein was extracted from frozen inoculated plant tissue. Extraction buffer (50 mM Sodium Phosphate/200 mM NaCl buffer at pH 7.5) was made with 20 $\mathrm{mM}$ Ascorbic Acid and $10 \mathrm{mM}$ Sodium Metabisulfite used as antioxidants. Tissue was homogenized at a 1:1 w/v ratio with extraction buffer. After blending, the homogenate was first filtered through two layers of Cheesecloth and one layer of Miracloth, then

centrifuged (Thermo Scientific ${ }^{\mathrm{TM}}$ Sorvall Legend XTR Centrifuge) at 15,000 x g for 15 minutes. This cloth filtering and centrifugation step was repeated, then the homogenate 
was filtered through 2 layers of Cheesecloth and 1 layer of Miracloth and stored at $4^{\circ} \mathrm{C}$ to incubate 12-16 hours. Following incubation, the homogenate was centrifuged at 15,000 x $\mathrm{g}$ for 15 minutes, then flowed through a $0.65 \mu \mathrm{m}$ glass fiber filter (Sartorius Stedim Biotech SartoScale Disposable) using a peristaltic pump. This homogenate was then 0.2 $\mu \mathrm{m}$ vacuum filtered (Thermo Scientific ${ }^{\mathrm{TM}}$ Nalgene $^{\mathrm{TM}}$ Rapid-Flow $^{\mathrm{TM}}$ Sterile Single Use). Samples were taken at each step and analyzed with SDS-PAGE.

\section{H. $\underline{\text { RBD-foldon Purification }}$}

\section{FPLC}

The $0.2 \mu \mathrm{m}$ filtered homogenate was immediately loaded for FPLC (GE ÄKTA Pure Chromatography System). RBD-foldon was isolated from the homogenate using Cobalt IMAC Column (GE TALON ${ }^{\circledR}$ Superflow ${ }^{\mathrm{TM}}$ Resin), measured to a column volume of $10 \mathrm{~mL}$, isolating RBD-foldon using the 6x histidine tag. The wash buffer (Buffer A) used was $50 \mathrm{mM}$ Sodium Phosphate with $200 \mathrm{mM} \mathrm{NaCl}$ at $\mathrm{pH}$ 7.5. Elution buffer (Buffer B) used was $50 \mathrm{mM}$ Sodium Phosphate, $200 \mathrm{mM} \mathrm{NaCl}$, and $500 \mathrm{mM}$ Imidazole at $\mathrm{pH}$ 7.5. A buffer gradient from $100 \%$ buffer $\mathrm{A} / 0 \%$ buffer $\mathrm{B}$ to $0 \%$ buffer A/100\% buffer B over 20 column volumes was used to separate and elute product. Samples were taken of chromatography wash, flow-through, and elution fractions and analyzed with SDS-PAGE.

\section{2. $\underline{\mathrm{UF} / \mathrm{DF}}$}

Following chromatography, RBD-foldon elution fractions were combined into one volume. Utilizing UF/DF, volume was buffer exchanged from imidazole-containing 
buffer to 1x phosphate-buffered saline (Intermountain Life Sciences), and concentrated. For UF/DF of RBD-foldon containing volume, 10,000 molecular weight cut-off/nominal molecular weight limit (MWCO/NMWL) centrifugal filters (Millipore Amicon ${ }^{\circledR}$ Ultra15 Ultracel ${ }^{\circledR}$ Regenerated Cellulose) were used with a centrifuge setting of 4,000 x g (Thermo Scientific ${ }^{\mathrm{TM}}$ Heraeus Multifuge X3R Centrifuge). Following UF/DF, the RBDfoldon containing retentate was $0.2 \mu \mathrm{m}$ centrifugal filtered (PALL Life Sciences Nanosep with $0.2 \mu \mathrm{m}$ wwPTFE). The concentration of $0.2 \mu \mathrm{m}$ filtered RBD-foldon containing retentate was determined using a spectrophotometer (Thermo Fisher Nanodrop ${ }^{\mathrm{TM}} 1000$ ) to obtain the absorbance at a wavelength of $280 \mathrm{~nm}$. Samples were taken of the load, permeate, and retentate and analyzed with SDS-PAGE. Additionally, the same samples run on SDS-PAGE were ran on Western Blots. For SDS-PAGE and Western Blotting, 10 $\mu \mathrm{g}$ and $1 \mu \mathrm{g}$ of RBD-foldon was loaded, respectively.

\section{Sample Collection}

A total of 128 human sera samples were collected. There were 82 total COVID positive samples. Of the positives, there were 46 hospitalized patient samples and 36 nonhospitalized patient samples. All positive samples were RT-PCR-positive and RBD IgG Seropositive, or either Spike IgG or IgM Seropositive. There were 46 total negative samples. Of the negatives, there were 33 pre-COVID negative samples, 11 pre-COVID negative HIV-positive samples, and 2 hospitalized patient samples (patients that were hospitalized during the pandemic for reasons not related to COVID-19). Hospitalized samples were obtained from Norton Hospital patients. Non-hospitalized samples were 
obtained from healthcare workers and Co-Immunity (University of Louisville IRB\# 20.0312). Negative samples were obtained from two biorepositories.

\section{J. RBD-foldon Serological ELISA}

All ELISAs were ran on 96-well microplates (Thermo Scientific) using RBDfoldon as the coating immunogen (Figure 2).

\section{Antigen Coating Optimization}

Initially, four coating concentrations were used to determine the optimal concentration of RBD-foldon. Microplates were coated with $100 \mu \mathrm{L}$ of each RBD-foldon concentration diluted in PBS with a multichannel repeater pipette (Eppendorf Xplorer 50$1200 \mu \mathrm{L})$. Plates were then placed in $4^{\circ} \mathrm{C}$ for $12-16$ hours, then washed three times with $300 \mu \mathrm{L}$ per well of PBS-T. This washing scheme was repeated after each step and done either manually using a multichannel repeater pipette or using a plate washer $\left(\operatorname{BioTek}{ }^{\circledR}\right.$ EL406). Next, all plates were blocked at room temperature for 1-2 hours with $300 \mu \mathrm{L}$ protein-free buffer (Thermo Scientific Pierce ${ }^{\mathrm{TM}}$ Protein-Free PBS Blocking Buffer) per well. During blocking, within a biosafety cabinet, 46 samples (23 hospitalized positive and 23 negatives) were diluted to 1:50 in protein free buffer. Plates were washed, then 50 $\mu \mathrm{L}$ of protein free buffer was added to each well of each plate. Samples were added in duplicate, leaving four blanks per plate to allow for the average background optical density (OD) to be obtained. $50 \mu \mathrm{L}$ of each 1:50 sera sample dilution was added to 92 wells total, resulting in a final dilution of $1: 100.50 \mu \mathrm{L}$ of protein free buffer was added to the remaining four wells. The plates were then incubated at $37^{\circ} \mathrm{C}$ for 30 minutes. During 
incubation, secondary antibody dilution was prepared. Rabbit anti Human IgG-HRP was diluted to 1:10000 in protein free buffer. Following incubation, plates were then washed in the biosafety cabinet, and $100 \mu \mathrm{L}$ of secondary antibody dilution was added to every well. The plates were then incubated at room temperature for 1 hour. Following incubation, plates were washed, and $100 \mu \mathrm{L}$ of room temperature TMB substrate (Thermo Scientific 1-Step ${ }^{\mathrm{TM}}$ Ultra TMB-ELISA) was added to every well. After 15 minutes, $100 \mu \mathrm{L}$ of stop solution $(1 \mathrm{~N} \mathrm{HCl})$ was added to the TMB in each well. Optical density (OD) of each well was read at a wavelength of $450 \mathrm{~nm}$ using a plate reader (BioTek ${ }^{\circledR}$ Synergy ${ }^{\mathrm{TM}}$ HT). Data was exported to excel for analysis.

\section{Antibody Class Specificity}

The $5 \mu \mathrm{g} / \mathrm{mL}$ RBD-foldon coating was used on all subsequent plates and the previous 23 hospitalized positive and 23 negative samples were replicated with IgG-HRP secondary antibody. An additional 23 hospitalized positive, 36 non-hospitalized positive, and 23 negative samples, along with a positive and negative control (positive control was 10-fold higher OD than the negative control) and blank, were assessed for IgG response, for a total of 82 positive and 46 negative samples. All samples were added to the plate in duplicate and each assay was replicated three times. The same 82 positive and 46 negative samples were evaluated for $\operatorname{IgA}$ and $\operatorname{IgM}$ responses by altering the secondary antibody. The rabbit anti Human IgA-HRP secondary antibody at 1:10,000 dilution in protein free buffer was used to assess IgA response and Rabbit anti Human IgM-HRP secondary antibody at 1:10,000 dilution in protein free buffer was used to assess IgM response. All plates were incubated with secondary antibody at room temperature for 1 
hour. Following incubation, plates were washed, and $100 \mu \mathrm{L}$ of room temperature TMB substrate was added to every well. After 15 minutes, $100 \mu \mathrm{L}$ of stop solution (1N HCl) was added to the TMB in each well. Optical density (OD) of each well was read at a wavelength of $450 \mathrm{~nm}$ using a plate reader. Data was exported to excel for analysis.

\section{Lot Variability}

ELISAs assessing the IgG response were performed as previously described using the IgG-HRP secondary antibody but with four freshly purified RBD-foldon lots. Each single lot was coated at $5 \mu \mathrm{g} / \mathrm{mL}$ on one half of a plate (i.e., Lot 1 coated on Plate 1: columns 1-6, Lot 2 coated on Plate 1: columns 7-12, Lot 3 coated on Plate 2: columns 16, Lot 4 coated on Plate 2: columns 7-12). All samples were tested in triplicate with; six positive samples, six negative samples, positive control, negative control, and blank per lot. Following analysis in Excel, analyzed data was input to Graphpad PRISM for further analysis.

\section{Antibody Titration}

IgG antibody titers to RBD-foldon were determined for all 82 positive samples. RBD-foldon was coated at $5 \mu \mathrm{g} / \mathrm{mL}$ on each plate. Six samples, positive/negative control, and blank were run per plate. Samples were analyzed in duplicate with three-fold serial dilutions, from 1:100 to 1:72,900. IgG-HRP was used as secondary antibody. Blocking, washing, incubation, and color development were the same as previously described. Data was exported to excel for analysis. 


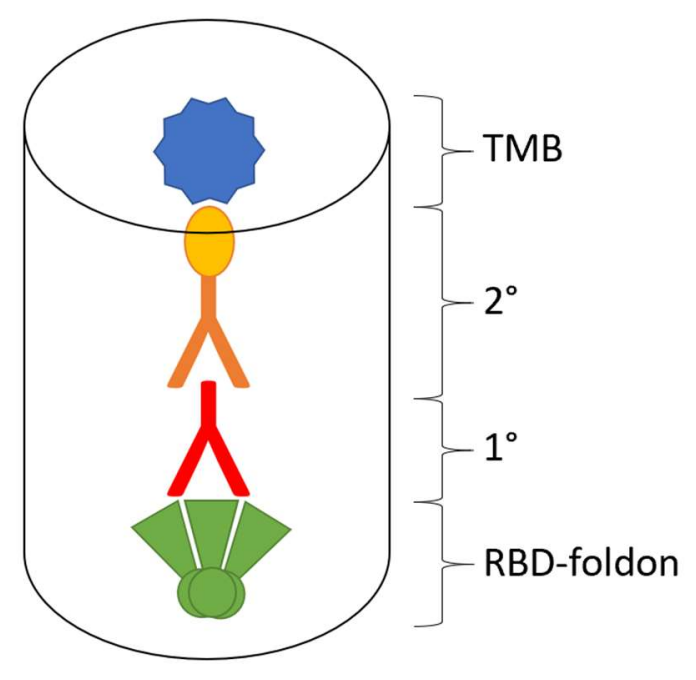

FIGURE 2 - RBD-foldon ELISA Layout ( $1^{\circ}$ Antibody: Human Sera anti-RBD, $2^{\circ}$ Antibody: Rabbit anti-Human HRP Conjugate, TMB: Reporter Enzyme)

\section{K. Data Analysis}

ELISA data was analyzed using Microsoft Excel or Graphpad PRISM. For ELISAs of each differing RBD-foldon coating (concentration or lot) or secondary antibody (IgG/IgA/IgM), the OD of blank wells were averaged, and subtracted from the OD of all sample containing wells. Then, the OD of sample duplicates/triplicates were averaged and used to generate Receiver Operator Characteristic (ROC) Curves to assess sensitivity and specificity of RBD-foldon ELISAs. For lot variability ELISAs only, analyzed data from excel was input to Graphpad PRISM, and assessed using a one-way ANOVA and Tukey test. For antibody titration, the OD of duplicate blanks were averaged and subtracted from all sample containing wells on each plate. Next, the OD of duplicate samples were averaged. The cutoff OD for antibody titer determination was set 
at $0.3 \mathrm{OD}$ absorbance units (AU) above that of the mean negative control OD. RBDfoldon antibody titers were plotted against PRNT50 titers and Pearson's $r$ values were generated to assess correlation of antibody titer values to SARS-CoV-2 viral neutralization. 


\section{RESULTS AND DISCUSSION}

A. Aim 1: Establish a reproducible purification method for plant expressed RBD-foldon.

In order to develop an RBD-foldon serological assay, a consistent expression

platform needed to be established. The tobacco mosaic virus (TMV) viral vector expression system was chosen due to its speed and consistency. TMV virion expressing RBD-foldon was extracted from Nicotiana benthamiana plants. TMV coat protein is 17.5 kilodaltons $(\mathrm{kD})$ in size and can be seen in Figure 3. Coat protein presence is associated with viral RNA translation (Liu \& Nelson, 2013), and therefore the presence of coat protein on the gel indicates that the viral vector had infected and was replicating throughout plants, and should be expressing RBD-foldon.

Following the establishment of a plant expression system for RBD-foldon, multiple extraction buffers were evaluated for protein extraction. The results of the extraction buffer panel indicated that buffer containing $50 \mathrm{mM}$ Sodium Phosphate, 200 mM Sodium Chloride, at $\mathrm{pH} 7.5$ was sufficient to extract RBD-foldon from Nicotiana benthamiana tissue (Figure 4). RBDFoldon extraction and purification samples were ran on SDS-PAGE (Figures 5 and 6). In figure 5, the large subunit of Rubisco is present at $50 \mathrm{kD}$. Rubisco is the main carboxylase of the Calvin cycle and the most prevalent enzymes in the biosphere (Flamholz et al., 2019). It contains a large subunit of $\sim 50 \mathrm{kD}$ and a small subunit of $10-15 \mathrm{kD}$ in size, either of which can be seen on SDS-PAGE when extracted in large enough quantities. In wells 2-9, TMV coat protein is present at 17.5 $\mathrm{kD}$, showing that the expression vector was translated in plant tissue. RBD-foldon is $31.485 \mathrm{kD}$ in size and can be seen as the dominant band in wells $10-13$, confirming RBD- 
foldon was isolated from the homogenate. In figure 6 , a band at $31.485 \mathrm{kD}$ was visible in the combined elution fraction sample (ultrafiltration/diafiltration load) and is the most prominent band in the ultrafiltration/diafiltration (UF/DF) retentate sample. Western Blotting confirmed that RBD-foldon was isolated, as a significant band reactive to 6x His antibody at $31.485 \mathrm{kD}$ was detected (Figure 7).

Four additional lots (5-8) of RBD-foldon were expressed and purified to examine lot-to-lot variability. The volume of plant tissue used to produce previous lots required the use of an automated chromatography system. Since the volume of plant tissue was significantly less than previously used, batch purification was performed (Figure 8). RBD-foldon lots 5, 6, 7, and 8 were concentrated to $2.13 \mathrm{mg} / \mathrm{mL}, 2.73 \mathrm{mg} / \mathrm{mL}, 1.92$ $\mathrm{mg} / \mathrm{mL}$, and $3.22 \mathrm{mg} / \mathrm{mL}$, respectively. The UF/DF of each lot can be seen in Figure 9, with $5 \mu \mathrm{g}$ of each lot ran in the "Retentate" lanes. To test the quality of each lot, the serological assay was run with each lot, using six positive samples, six negative samples, positive and negative control, and blank. Lot 5 was then used as a reference for lots 6, 7, and 8 . The percent difference in absorbance between samples tested on each lot relative to lot 5 was determined.

A one-way ANOVA and Tukey's post-hoc tests were run to compare the variance of negative sample absorbance between lots 6, 7, and 8 and Positive Sample optical densities between lots 6, 7, and 8 (Figure 10). No statistical differences were observed in response to any of the three lots $(\alpha=0.05)$. Therefore, it was concluded that RBD-foldon can be reproduced using the methods previously described with no statistical difference in sera response between lots. 


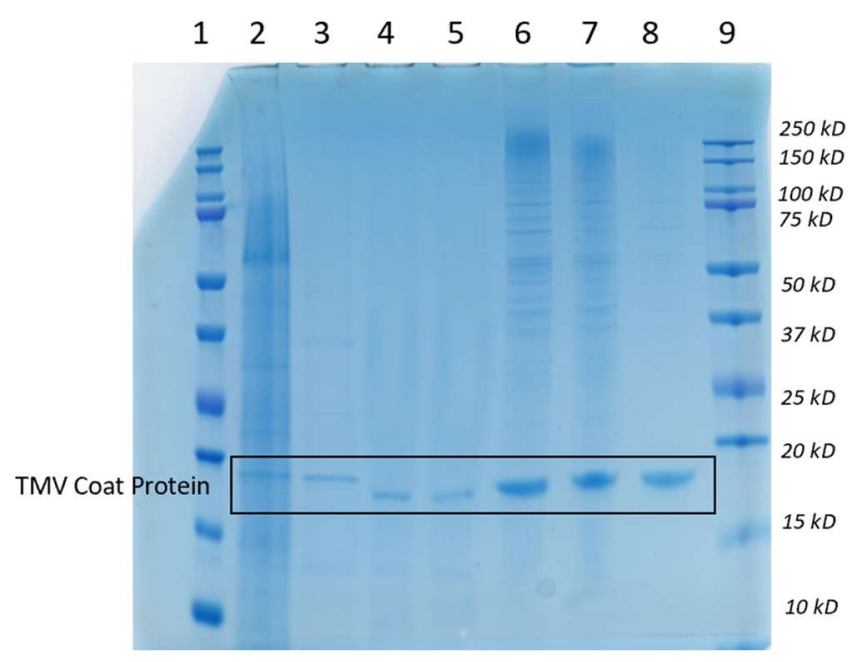

FIGURE 3 - Virion Extraction SDS-PAGE [Order from left to right: (1) protein ladder (2) homogenate supernatant post centrifugation (3) miracloth and cheesecloth filtered supernatant (4) post addition of PEG (5) post 2-hour incubation (6) pellet resuspension (7) post 24-hour incubation (8) post centrifugation and miracloth filtration (9) protein ladder]

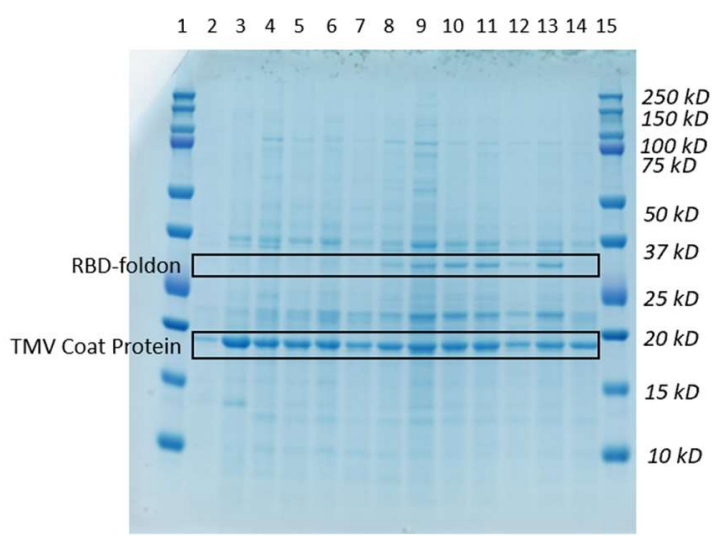

FIGURE 4 - RBD-foldon Extraction Buffer Panel SDS-PAGE [Order from left to right: (1) protein ladder (2\&3) $50 \mathrm{mM}$ Sodium Acetate $\mathrm{pH} 4 \mathrm{w} / \mathrm{o}$ and w/200mM NaCl (4\&5) 50mM Sodium Acetate $\mathrm{pH} 5$ w/o and w/200mM NaCl (6\&7) 50mM Sodium Phosphate pH 6 w/o and w/200mM NaCl (8\&9) 50mM Sodium Phosphate pH 7.5 w/o and $w / 200 \mathrm{mM} \mathrm{NaCl}(10 \& 11) 50 \mathrm{mM}$ Tris $\mathrm{pH} 9 \mathrm{w} / \mathrm{o}$ and $w / 200 \mathrm{mM} \mathrm{NaCl}$ (12\&13) 50mM Tris pH $10 \mathrm{w} / \mathrm{o}$ and w/200mM $\mathrm{NaCl}$ (14) $1 x$ XTMES (15) protein ladder] 


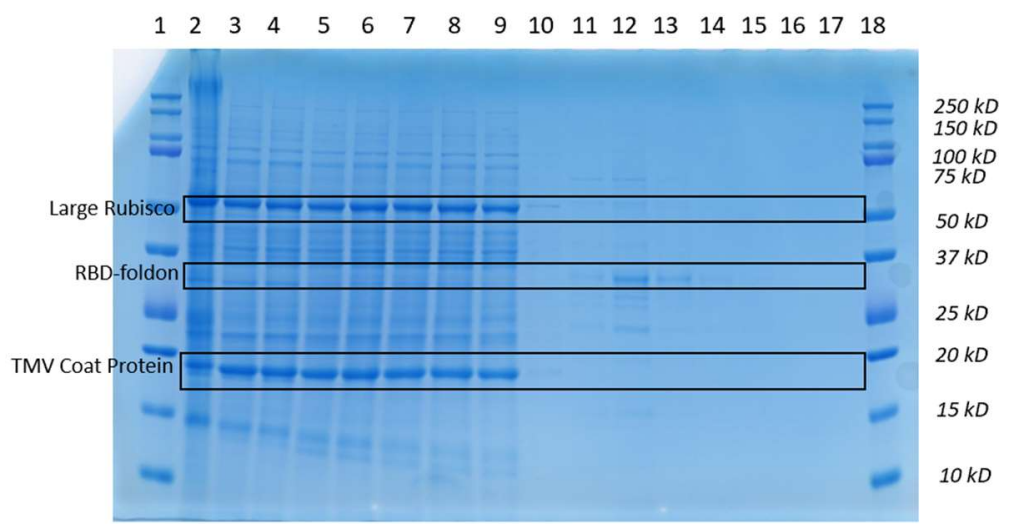

FIGURE 5 - RBD-foldon Extraction and Cobalt Affinity Chromatography SDS-PAGE [Order from left to right: (1) protein ladder (2) Miracloth and cheesecloth filtered homogenate (3) Post $1^{\text {st }}$ Centrifugation (4) Post $2^{\text {nd }}$

Centrifugation (5) Post 16 hour $4^{\circ} \mathrm{C}$ incubation (6) Post $3^{\text {rd }}$ Centrifugation (7) Post $0.65 \mu m$ Glass Fiber filtration (8) Post $0.2 \mu \mathrm{m}$ bottle-top vacuum filtration (9) IMAC flow through (10) IMAC Wash (11-17) Elution fractions 1A1-1A5, 1B1-1B3 (18) protein ladder]

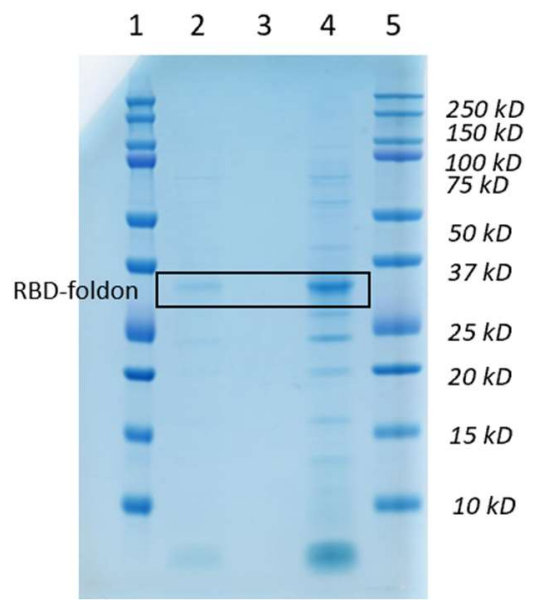

FIGURE 6 - RBD-foldon Ultrafiltration/Diafiltration SDS-PAGE [Order from left to right: (1) protein ladder (2) Load - combined IMAC elution fractions 1A1-1A4 (3) Permeate (4) Retentate (5) protein ladder] 


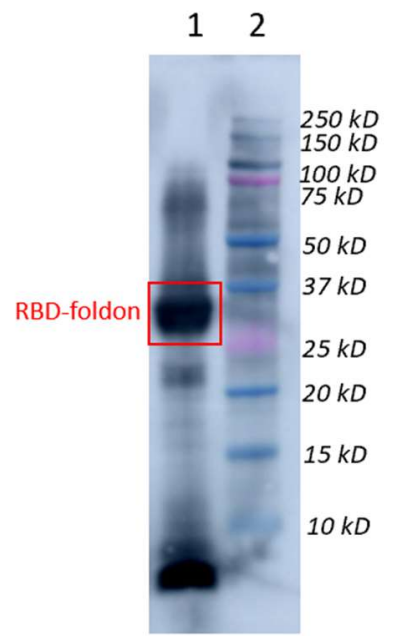

FIGURE 7 - RBD-foldon Final Product anti-Histidine Tag Western Blot [Order from left to right: (1) Retentate (2) protein ladder]

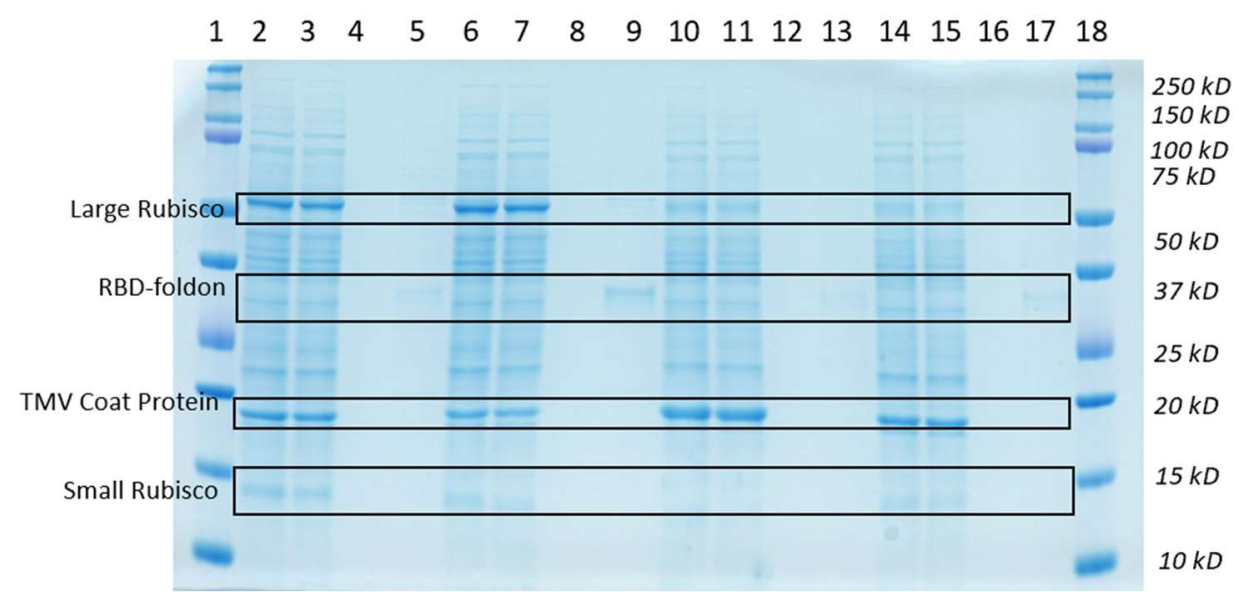

FIGURE 8 - Lot Variability Batch Purification SDS-PAGE [Order from left to right: (1) protein ladder $(2,6,10,14)$ Lot 5-8 0.2 4 m filtered homogenate $(3,7,11,15)$ Lot 5-8 Flow through $(4,8,12,16)$ Lot 5-8 Wash $(5,9,13,17)$ Lot 5-8 Eluate (18) protein ladder] 


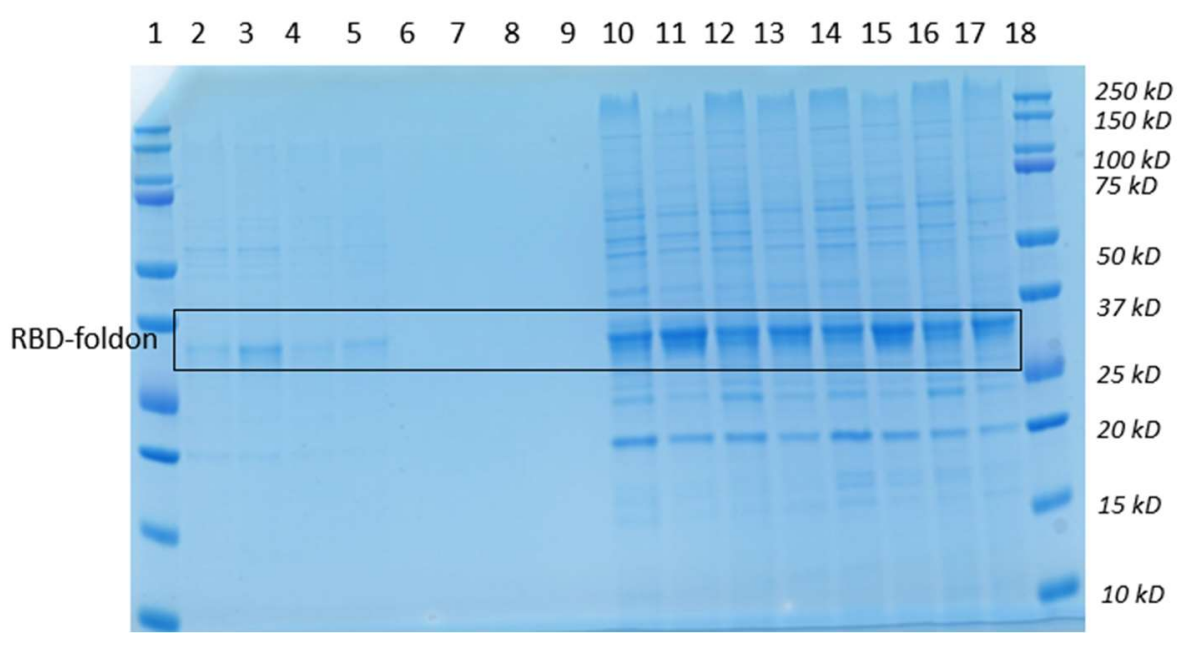

FIGURE 9 - Lot Variability UF/DF SDS-PAGE [Order from left to right: (1) protein ladder (2-5) Lot 5-8 Eluate (6-9) Lot 5-8 Permeate (10-13) Lot 5-8 Retentate (14-17) Lot 5-8 0.2 $\mu$ m filtered Retentate (18) protein ladder]

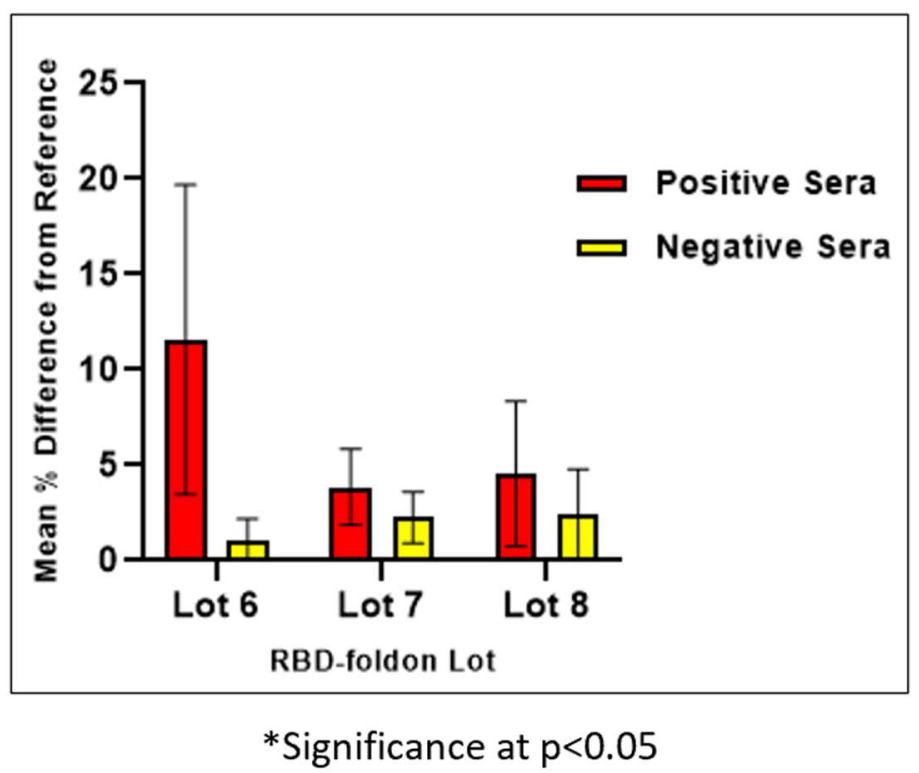

FIGURE 10 - Mean Percent Difference of Lots 6-8 from Reference (Positive Samples $n=6$, Negative Samples $n=6$ ) 
B. Aim 2: Establish a serological assay using RBD-foldon as the target antigen.

Running SDS-PAGE and western blotting of RBD-foldon allowed for verification of the expression and isolation of RBD-foldon, and RBD-foldon -targeting serological ELISA development could begin. The first step in assay development was determining coating concentration of RBD-foldon. In developing serological assays for detecting viral responses, high sensitivity and specificity are imperative. Sensitivity relates to the probability of correctly identifying a positive sample, or True Positive Rate (TPR). For example, the highest possible sensitivity of 1 means that $100 \%$ of positive samples will be correctly identified by the assay. Conversely, specificity relates to the probability of correctly identifying a negative sample, or True Negative Rate (TNR). So, the highest possible specificity of 1 means that $100 \%$ of negative samples will be correctly identified by the assay. As the sensitivity decreases, the probability of incorrectly identifying a positive sample as negative, or the False Negative Rate (FNR), increases. Similarly, as the specificity decreases, the probability of incorrectly identifying a negative sample as positive, or the False Positive Rate (FPR), increases. ROC Curves were generated to examine the relationship between true positive rate and false positive rate and determine an acceptable cutoff optical density value for identifying positive and negative samples. For the RBD-foldon serological assay, the optimal cutoff optical density value is characterized by both a high true positive rate $(\geq 90 \%)$ and low false positive rate $(\leq 10 \%)$.

ELISAs were ran with four coating concentrations - from low to high: $0.5 \mu \mathrm{g} / \mathrm{mL}$, $1 \mu \mathrm{g} / \mathrm{mL}, 2.5 \mu \mathrm{g} / \mathrm{mL}$, and $5 \mu \mathrm{g} / \mathrm{mL}$. At 100\% sensitivity (TPR=100\%), for RBD-foldon coating concentrations of $0.5,1,2.5$, and $5 \mu \mathrm{g} / \mathrm{mL}$, the optimal OD cutoffs are 0.09175 , 
0.1905, 0.278, and 0.47925, respectively (indicated by yellow points in Figure 11A-D). These OD cutoffs would yield specificities of $34.78 \%, 95.65 \%, 82.60 \%$, and $95.65 \%$, respectively. Conversely, at 100\% specificity (TNR=100\%), for RBD-foldon coating concentrations of $0.5,1,2.5$, and $5 \mu \mathrm{g} / \mathrm{mL}$, the optimal OD cutoffs are $0.17975,0.256$, 0.4535, and 0.71125, respectively (indicated by red points in Figure 11A-D). These OD cutoffs would yield sensitivities of $65.22 \%, 86.95 \%, 95.65 \%$, and $95.65 \%$, respectively (Figure 11A-D).

At $100 \%$ sensitivity or $100 \%$ specificity, $0.5 \mu \mathrm{g} / \mathrm{mL}$ yielded both the lowest specificity and sensitivity of the four concentrations. This produced largely inaccurate identification of positive and negative samples and suggests that $0.5 \mu \mathrm{g} / \mathrm{mL}$ coating was not able to elicit sufficient binding of SARS-CoV-2 induced IgG antibodies. Therefore $0.5 \mu \mathrm{g} / \mathrm{mL}$ was not an optimal coating concentration. At $100 \%$ sensitivity, $1 \mu \mathrm{g} / \mathrm{mL}$ coating had the lowest specificity, while 2.5 and $5 \mu \mathrm{g} / \mathrm{mL}$ had the same specificity. Conversely, at $100 \%$ specificity, $2.5 \mu \mathrm{g} / \mathrm{mL}$ coating had the lowest sensitivity, while 1 and $5 \mu \mathrm{g} / \mathrm{mL}$ had the same sensitivity. When sensitivity or specificity is at $100 \%$, while 1 $\mu \mathrm{g} / \mathrm{mL}$ and $2.5 \mu \mathrm{g} / \mathrm{mL}$ coatings do yield high specificity/sensitivity, $5 \mu \mathrm{g} / \mathrm{mL}$ coating concentration yields a sensitivity or specificity that is equal to or higher than both 1 $\mu \mathrm{g} / \mathrm{mL}$ and $2.5 \mu \mathrm{g} / \mathrm{mL}$. Additionally, comparing the deviation between optical densities of $1 \mu \mathrm{g} / \mathrm{mL}, 2.5 \mu \mathrm{g} / \mathrm{mL}$, and $5 \mu \mathrm{g} / \mathrm{mL}$ (Table I), $5 \mu \mathrm{g} / \mathrm{mL}$ has the greatest deviation in OD between positive and negative samples, further supporting the selection of $5 \mu \mathrm{g} / \mathrm{mL}$ as the concentration to proceed with the following studies. 
TABLE I

RBD-foldon Coating Concentration Optical Densities (Row 1) Highest Negative OD (Row 2) Lowest-Positive/Cut-off OD at $100 \%$ Specificity

\begin{tabular}{|c|c|c|c|c|} 
& $\mathbf{0 . 5} \boldsymbol{\mu g} / \mathbf{m L}$ & $\mathbf{1} \boldsymbol{\mu g} / \mathbf{m L}$ & $\mathbf{2 . 5} \boldsymbol{\mu g} / \mathbf{m L}$ & $\mathbf{5} \boldsymbol{\mu g} / \mathbf{m L}$ \\
\cline { 2 - 5 } Highest Negative OD & 0.17925 & 0.241 & 0.3685 & 0.58075 \\
\cline { 2 - 5 } Lowest Positive OD & 0.17975 & 0.256 & 0.4535 & 0.71125 \\
\cline { 2 - 5 } & &
\end{tabular}
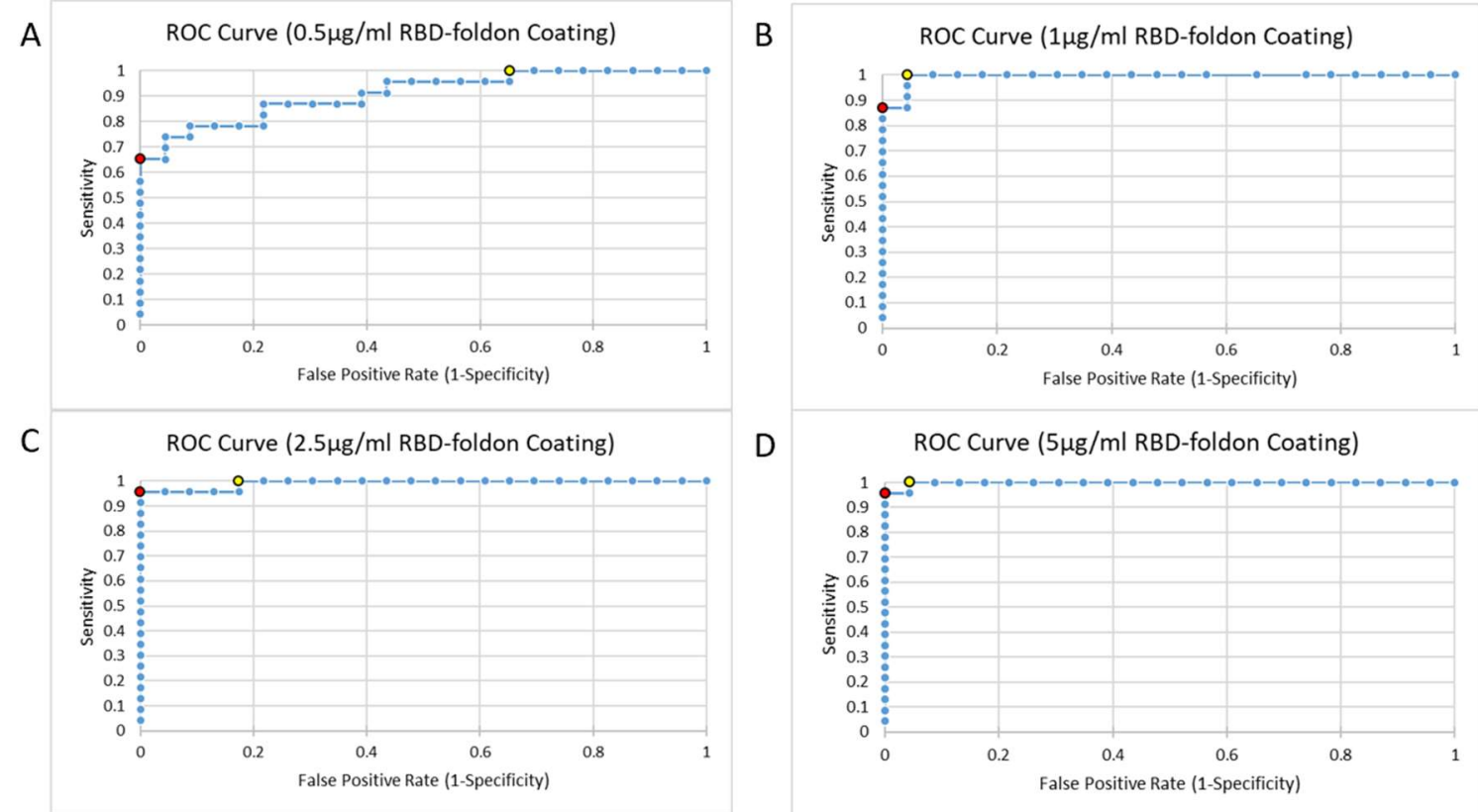

FIGURE 11 - ROC Curves for Varying RBD-foldon Coating IgG Responses (positive sample n=23, negative sample $\mathrm{n}=23$ ) (A) $0.5 \mu \mathrm{g} / \mathrm{mL}$ (B) $1 \mu \mathrm{g} / \mathrm{mL}$ (C) $2.5 \mu \mathrm{g} / \mathrm{mL}$ (D) $5 \mu \mathrm{g} / \mathrm{mL}$

A key relationship is that, for serological assays, as specificity of the assay increases, sensitivity decreases, and as sensitivity of the assay increases, specificity 
decreases. The magnitude of this inverse relationship differs between assays. In choosing a cutoff OD for SARS-CoV-2 serological assays, two scenarios must be considered: 1) a specificity of $100 \%$ will correctly classify all individuals with antibodies but increase the probability of telling an individual they do not have antibodies when they do (a false negative diagnosis) and 2) a sensitivity of $100 \%$ will correctly classify all individuals without antibodies but increase the probability of telling an individual they have antibodies when they do not (a false positive diagnosis). The former maximizes specificity, sacrificing a percentage of assay sensitivity. The latter maximizes sensitivity, sacrificing a percentage of assay specificity. Assuming all antibodies are protective, individuals that are given a false positive result will be at risk for infection, potentially resulting in a decrease in adherence to practices that reduce viral spread and an increase in cases. Individuals that are given a false negative result will not be at the risk of infection and would not pose a negative societal impact on reducing viral spread. Considering each scenario, a cutoff OD should be chosen that yields both high sensitivity and specificity, but with emphasis placed on maximizing specificity.

Hospitalized samples yielded a specificity of $95.65 \%$ and sensitivity of $93.4 \%$ (Figure 12A), while Non-Hospitalized samples yielded a specificity of $95.65 \%$ and sensitivity of $86.11 \%$ (Figure 12B). Plotting both hospitalized and non-hospitalized positives sera samples together, they yielded a specificity of $95.65 \%$ and sensitivity of 90.24\% (Figure 12C). When comparing the separate ROC curves for hospitalized positives and non-hospitalized positives, they yielded the same specificity and similar sensitivity, at similar cutoff optical densities. For the non-hospitalized positives, a cutoff 
of 0.787 was determined, while for the hospitalized positives, the cutoff determined was 0.831. Plotting all positives together, a cutoff of 0.787 was determined. Cutoff OD were determined by selecting an OD that yielded the highest possible sensitivity with a specificity of at least $95 \%$.

After determining sensitivity and specificity, positive and negative predictive value (PPV and NPV) can be calculated. Assay PPV and NPV are determined based on sensitivity, specificity, and disease prevalence. Prevalence is a measure of the percentage of a population affected by a disease at a given timepoint and varies depending on what geographic area and timepoint it is measured across and within. Prevalence is calculated by taking the sum of the number of true positives and negatives and dividing that by the number of true positives, true negatives, false positives, and false negatives. PPV is defined as the probability that those who test positive are true positives, while the NPV is defined as the probability that those who test negative are true negatives. For example, with a specificity of $95 \%$ and sensitivity of $90 \%$, for a high prevalence i.e., $50 \%$, the PPV and NPV will both be above 90\%, with PPV higher than NPV. For a lower prevalence i.e., $10 \%$, the PPV will drop to $\sim 70 \%$, while the NPV will increase to $\sim 99 \%$. This means that for a geographical region with a lower prevalence, the probability that those who test negative are true negatives is very high. For the present assay, the negative predictive value is very important as a high value would show that the assay can identify the majority of individuals in the region that have not been exposed and/or do not have protection from SARS-CoV-2, aiding individuals in adhering to guidelines that would protect them from contracting SARS-CoV-2. 
A

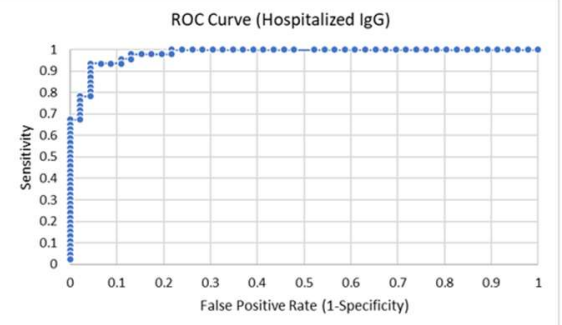

B

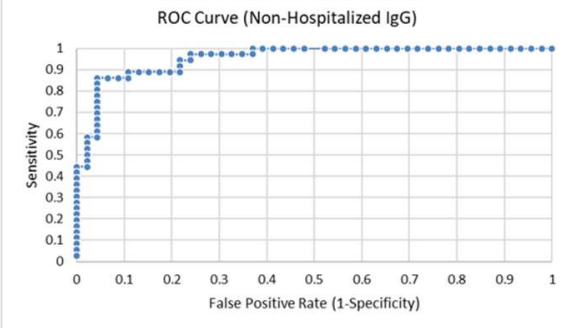

C ROC Curve (Hospitalized and Non-Hospitalized IgG)

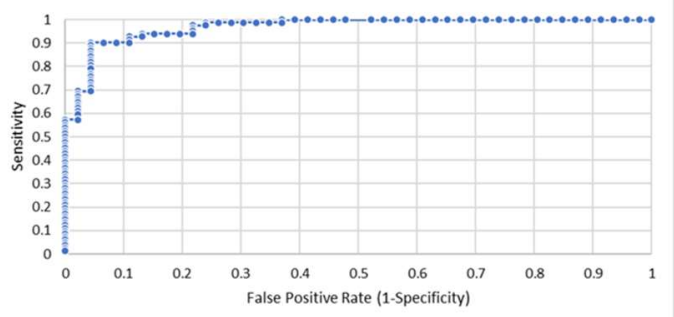

FIGURE 12 - ROC Curves for Patient IgG Response $(A)$ Hospitalized Positive sera $n=46$, Negative sera $n=46$ (B) Non-Hospitalized Positive sera n=36, Negative sera $n=46$ (C) All (Hospitalized and Non-Hospitalized) Positive sera $n=82$, Negative $\operatorname{sera} n=46$

To examine antibody class specificity to RBD-foldon, ROC curves were constructed and examined for patient $\operatorname{IgA}$ and $\operatorname{IgM}$ responses. A method for determining optimal cutoff OD is choosing the point closest to the $(0,1)$ corner of the ROC curve. The closer the curve to the $45^{\circ}$ diagonal, the less accurate the test. Using this method for the IgA ROC curve in Figure $13 \mathrm{~A}$, the optimal OD was 0.253 , with sensitivity and specificity of $60.98 \%$ and $80.43 \%$, respectively. Using the same method that was used to determine IgA sensitivity and specificity, from the IgM ROC curve in Figure 13B, the optimal OD was 0.5453 , with sensitivity and specificity of $70.73 \%$ and $82.61 \%$, respectively. 
The sensitivity and specificity for IgA was very low. Sensitivity and specificity of $\operatorname{IgM}$ was higher than that of $\operatorname{IgA}$, but not as high as IgG. During infection, $\operatorname{IgM}$ is produced before IgG but declines in concentration, comparatively, as the number of IgG antibodies increase (Younes et al., 2020). IgA antibodies are typically protective however, they may be specific for other epitopes of the Spike protein besides RBD, explaining the low response to an RBD antigen (Sterlin et al., 2021). Additionally, IgM and IgA antibodies have varying seroconversion times and are less prevalent in sera than IgG antibodies (Long et al., 2020; Sterlin et al., 2021; Younes et al., 2020). Considering this, and due to the varying timepoints of infection for each collected sera sample used, IgM and IgA could be used qualitatively to determine general exposure to SARS-CoV-2 but would not be good markers of serological diagnosis (Ma et al., 2020; Sterlin et al., 2021).

A

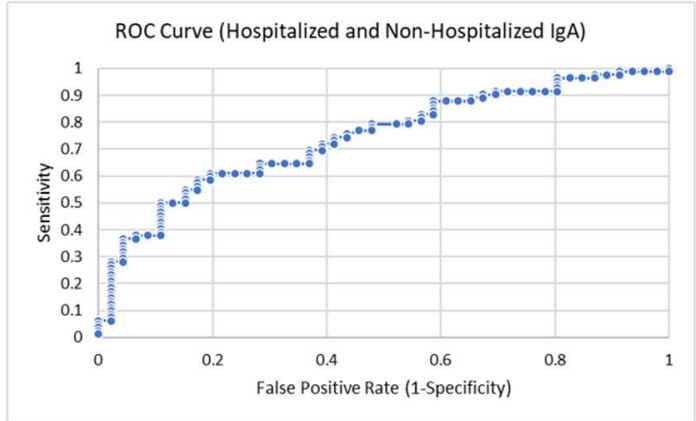

B

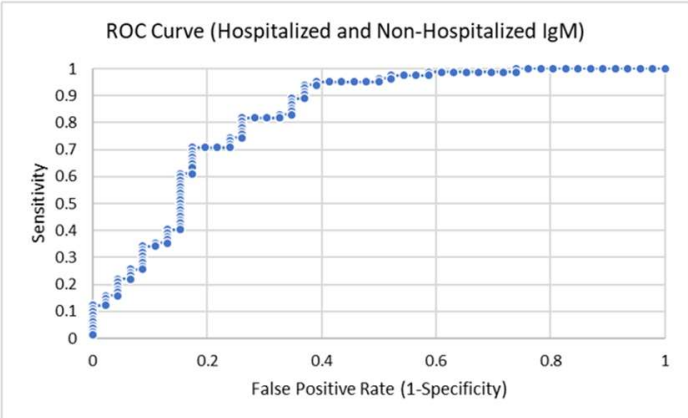

FIGURE 13 - ROC Curves for Patient IgA and IgM Response (A) IgA Response of all Positive sera $n=82$, Negative sera $n=46$ (B) IgM Response of all Positive sera $n=82$, Negative sera $n=46$ 
C. Aim 3: Assess the efficacy of RBD-foldon as an antigen for sera immunoglobulins, examining the correlation between immunoglobulin binding of RBD-foldon and viral $\underline{\text { neutralization. }}$

For hospitalized positive sera, all samples elicited an endpoint titer dilution of at least 1:100. Two samples produced a titer of 1:100, 15 samples produced a titer of 1:300, 22 samples produced a titer of 1:900, four samples produced a titer of 1:2700, and three samples produced a titer of 1:8100 (Figure 14). For non-hospitalized positive sera, two samples produced no titer (endpoint dilution $<1: 100$ ), three samples produced a titer of $1: 100,18$ samples produced a titer of $1: 300,10$ samples produced a titer of $1: 900$, two samples produced a titer of 1:8100, and one sample produced a titer of 1:24300 (Figure 15). Endpoint titers of patients with mild SARS-CoV-2 infection should be lower than those with moderate or severe SARS-CoV-2 infection (Ma et al., 2020).

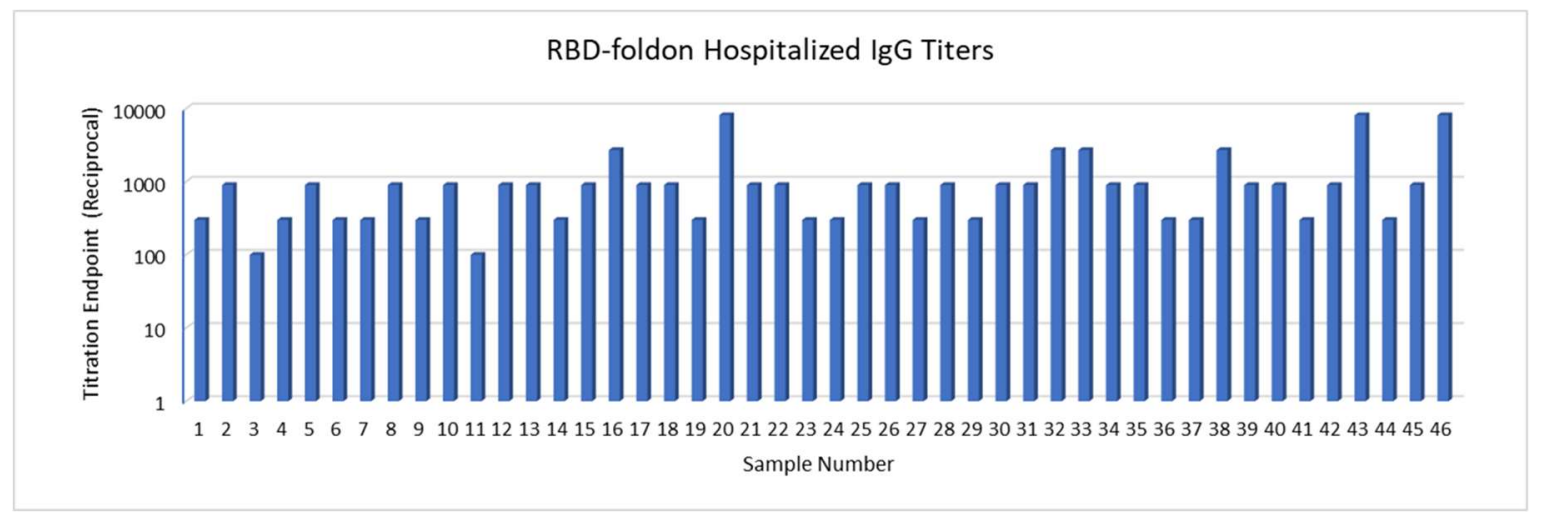

FIGURE 14 - RBD-foldon Hospitalized IgG Titers 


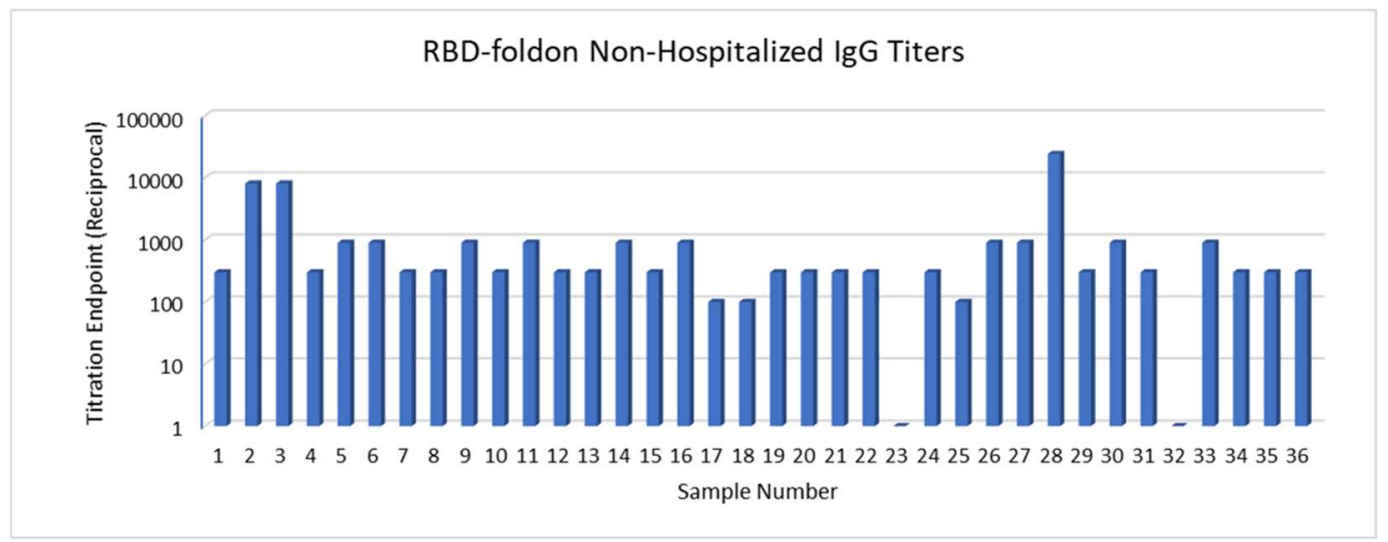

FIGURE 15 - RBD-foldon Non-Hospitalized IgG Titers

RBD-foldon endpoint titer dilution values were plotted against PRNT50 values. PRNT50 is the quantitative value obtained from a Plaque Reduction Neutralization Assay and is quantified as the inverse of the highest sera dilution producing $50 \%$ viral plaque neutralization. Plaque Reduction Neutralization Assays assess sera for neutralizing antibodies by measuring the amount of viral plaque neutralization (Timiryasova et al., 2013). To quantitatively assess correlation of RBD-foldon endpoint titers to PRNT50 values, linear fit lines were added, and Pearson's $r$ values were generated. It was determined that both non-hospitalized and hospitalized positive endpoint titers were positively correlated with PRNT50 values. Non-hospitalized positive endpoint titers plotted against PRNT50 produced an $r$ value of 0.5964 , or 59.64\% (Figure 16A). Hospitalized positive endpoint titers plotted against PRNT50 produced an $r$ value of 0.4869 , or $48.69 \%$ (Figure $16 \mathrm{~B})$. 
The $r$ value produced for non-hospitalized positive samples was higher than the $r$ value for hospitalized samples. Overall, PRNT50 values for hospitalized positive sera $(M=9507.63)$ were higher than those for non-hospitalized positive sera $(M=2101.16)$. Additionally, the standard deviation of PRNT50 values for hospitalized positive sera $(\mathrm{SD}=16705.97)$ was much greater than that for non-hospitalized positive sera $(\mathrm{SD}=4923.70)$. This may be due to increased variability of immune response in patients with moderate and severe infection (Ma et al., 2020).

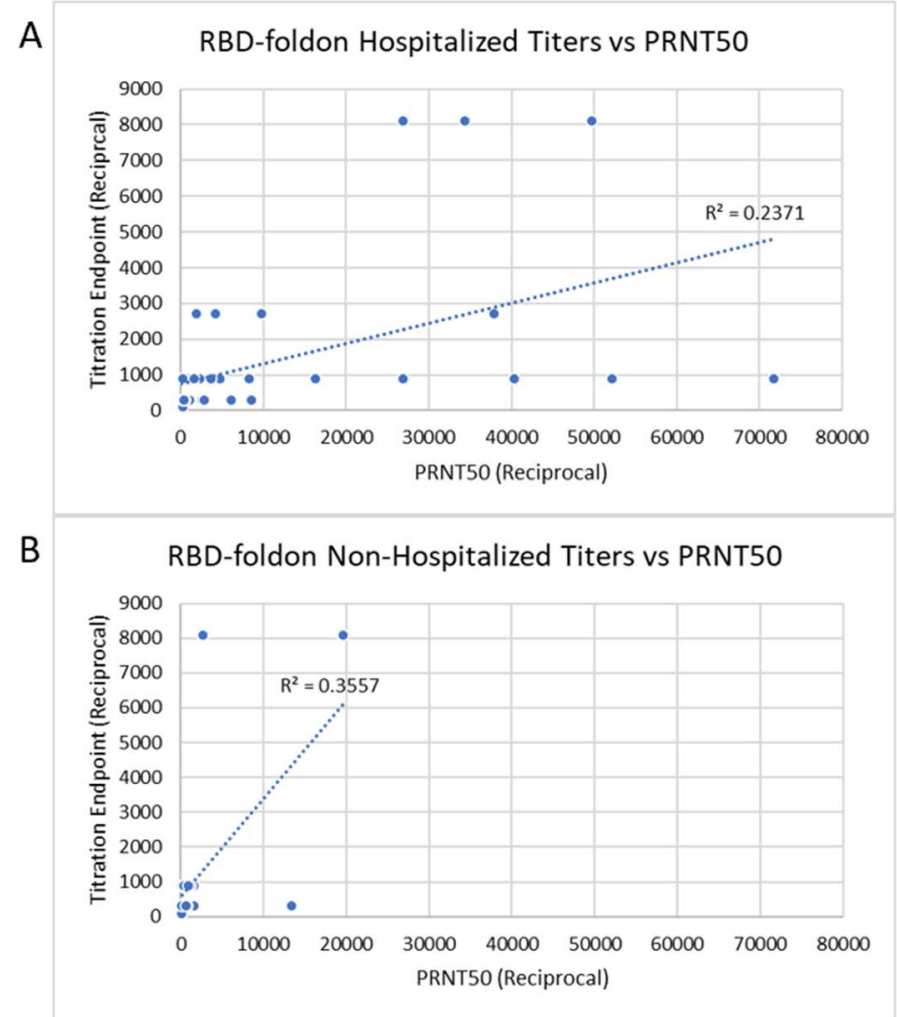

FIGURE 16 - RBD-foldon IgG Endpoint Titers vs PRNT50 (A) Hospitalized Positive sera titers $n=46$ vs PRNT50 Values $n=46$ (B) Non-Hospitalized Positive sera titers $n=21$ vs PRNT50 Values $n=21$ 
Out of the 46 hospitalized positive patient sera samples titrated with RBD-foldon, 18 of them had been titrated with monomeric RBD. Using these 18 positive samples, RBD-foldon and RBD endpoint titers were plotted against each other to determine how closely they correlated. This produced an $r$ value of 0.9645 , indicating that they are $96.45 \%$ correlated (Figure 17A). With an $r$ value of 0.9645 , it was presumed that RBDfoldon endpoint titers should correlate with PRNT50 values at comparable levels to RBD. To confirm this, RBD-foldon endpoint titers and RBD endpoint titers were plotted against PRNT50 values for the 18 positive samples. The $r$ value produced by RBDfoldon correlation with PRNT50 was 0.5427 , or $54.27 \%$ (Figure 17B). The $r$ value produced by RBD correlation with PRNT50 was 0.5903 , or $59.03 \%$ (Figure 17C). Predictably, the $r$ values for RBD-foldon and RBD differed by a small margin of 0.0476 , or $8 \%$. Notably, RBD-foldon endpoint titers $(\mathrm{M}=1855.56)$ were overall higher than RBD endpoint titers $(M=1777.28)$, suggesting that RBD-foldon may elicit higher levels of antibody binding than RBD. The higher $r$ value may indicate that RBD is more predictive of protection than RBD-foldon, however, further statistical analysis will be needed to determine if there is a significant difference between the $r$ values. 


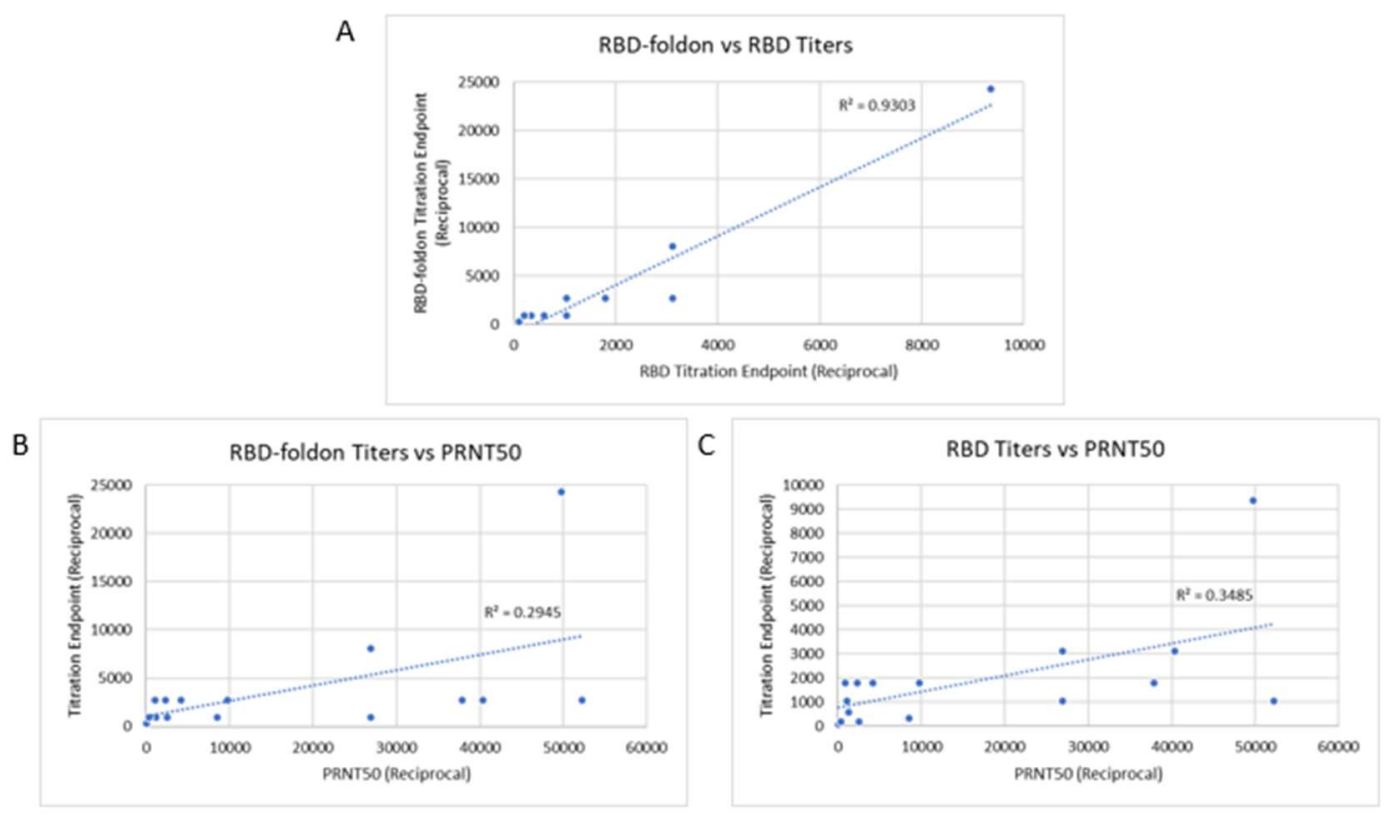

FIGURE 17 - IgG Endpoint Titer Comparison of RBD-foldon and RBD, n=18 (A) RBD-foldon vs RBD Endpoint Titers (B) RBD-foldon Endpoint Titers vs PRNT50 Values (C) RBD Endpoint Titers vs PRNT50 Values 


\section{CONCLUSIONS}

In the present study, a novel SARS-CoV-2 RBD antigen was developed and assessed for SARS-CoV-2 serological detection. Presented in Aim 1, a reproducible purification method for plant-expressed RBD-foldon was established. RBD-foldon was sufficiently expressed in Nicotiana benthamiana plants using Tobacco Mosaic Virus. RBD-foldon was successfully extracted and subsequently purified, then verified on SDS PAGE and Western Blotting. After producing multiple lots, they were not statistically significant from each other; therefore, RBD-foldon is reproducible. As detailed in Aim 2 and Aim 3, a serological ELISA was established with RBD-foldon as the target antigen. RBD-foldon ELISA absorbances were higher than that for RBD ELISAs, suggesting that RBD-foldon exhibited better binding of SARS-CoV-2 RBD-targeting antibodies than RBD. Additionally, it was determined that RBD-foldon coated at $5 \mu \mathrm{g} / \mathrm{mL}$ can detect SARS-CoV-2 RBD-targeting IgG antibodies with a specificity of $95.65 \%$ and sensitivity of $90.24 \%$. RBD-foldon binds IgA and IgM antibodies; however, further research using samples at uniform infection timepoints would be needed to characterize this response. Expectedly, non-hospitalized positive sample RBD-foldon IgG PRNT50 values were lower than hospitalized positive sample IgG PRNT50 values. RBD positive sample IgG endpoint titers were lower than RBD-foldon positive sample endpoint titers overall however, RBD-foldon and RBD were $96.45 \%$ correlated. RBD-foldon endpoint titers and PRNT50 values were positively correlated, suggesting that RBD-foldon can elicit a response from protective RBD-targeting antibodies. As endpoint titers for RBD-foldon and RBD are $96.45 \%$ correlated, correlation of each with PRNT50 values were similar. 
The $r$ value for RBD correlation with PRNT50 values was 0.5903 , while the $r$ for RBDfoldon correlation with PRNT50 values was 0.5427. Neither of the $r$ values were 1 , due to there likely being other binding regions of SARS-CoV-2 protective antibodies besides RBD. It was demonstrated that Foldon can be used as a trimerization domain for recombinant SARS-CoV-2 RBD. Additionally, it was shown that RBD-foldon can be used as strong antigen for serological testing. The findings in this study provide a platform for the development of novel viral antigens to aid in the understanding of viral function and host immune response. 


\section{RECOMMENDATIONS}

\section{A. Future Improvements}

RBD-foldon protein purity was characterized using SDS-PAGE and Western Blotting. Mass spectrometry of RBD-foldon was not performed; however, it would provide deeper insight into the mass-to-charge ratio of RBD-foldon and purity. Mass spectrometry would also provide information to determine the identity of the protein species seen at 5-10 kD on SDS-PAGE and Western Blots ran in this study.

For an FDA Emergency Use Authorization (EUA), antigens used for SARS-CoV2 serological tests need to be tested with IgG and/or IgM antibodies specific for the endemic coronaviruses responsible for the common cold (alpha-coronaviruses HCoV229E, -NL63 and beta-coronaviruses HCoV-OC43, -HKU1), influenza A and B, HCV, HBV, HIV, Haemophilus influenzae, and respiratory syncytial virus. The only virus targeting antibodies that RBD-foldon was tested with were anti-HIV. Testing with potential cross-reactive viruses would need to be done with RBD-foldon to receive an emergency use authorization as an antigen for SARS-CoV-2 serologicals.

The optimal cutoff absorbance chosen for this RBD-foldon assay was determined after testing all sera samples with one lot of RBD-foldon. To make a statistically sound decision on the optimal cutoff, testing of all samples in this study would need to be repeated with at least two more lots of RBD-foldon. An average optimal cutoff absorbance for the assay could be generated using the cutoff value determined for each lot. 
The RBD-foldon produced in this study was shown to be efficacious as an antigen, however, there may be structural factors that hinder it from expressing better in plants, and performing even better as an antigen, yielding higher optical densities, and potentially being more predictive of protection than determined in this study. These factors may lie in the signal peptide and/or RBD-to-foldon linker used. The signal peptide sequence used can impact the amount of plant expression, while the linker sequence used can impact protein stability. As seen in the SDS-PAGE in the results section, there is a protein species at $5-10 \mathrm{kD}$. This might be due to instability of the linker, resulting in both foldon protein and full-length RBD-foldon protein in the same eluate fractions, as they both would bind and elute during metal affinity chromatography due to the his-tag on both species.

\section{B. Future Applications}

With the emergence of SARS-CoV-2 variants B.1.1.7, B.1.351, and P.1, there is a need to characterize existing antibody responses to them. Characterizing antibody responses to these variants would allow for epidemiological measures to be taken to track and prevent their spread. SARS-CoV-2 variants that have and have yet to emerge may have mutations that affect the conformation and function of the Spike protein and RBD, potentially increasing infectivity and virulence. Serological testing can determine if antibodies to native SARS-CoV-2 are able to recognize variant RBDs. Using foldon to make trimeric variant RBD antigens may enhance testing and allow for more robust results. 
Foldon has been shown to be a trimerization domain for production of recombinant trimeric viral proteins. This study further supports this and demonstrates an example for Foldon fused protein production. Foldon can be fused to trimeric proteins of other viruses, producing recombinant trimeric viral proteins that can then be investigated in various studies as antigens for vaccines or diagnostics. This study presents a template for serology test development using Foldon fused antigens for detection of antibody responses to viral proteins.

Foldon fused antigens can also be used for vaccine development. It has been demonstrated in mice that foldon fused MERS-CoV RBD and foldon fused SARS-CoV spike protein can be used to elicit neutralizing antibody titers. This has yet to be demonstrated using foldon fused to SARS-CoV-2 RBD or spike protein in a mouse model. Therefore RBD-foldon may have efficacy as a vaccine immunogen and investigating the immunogenic potential of the plant-made RBD-foldon discussed in this thesis may yield promising results. 
APPENDIX I - SERA SAMPLE DATA

\begin{tabular}{|c|c|c|c|c|c|c|}
\hline Sample & Classification & $\begin{array}{c}\text { IgM } \\
\text { Absorbance }\end{array}$ & $\begin{array}{c}\text { IgA } \\
\text { Absorbance }\end{array}$ & $\begin{array}{c}\text { IgG } \\
\text { Absorbance }\end{array}$ & $\begin{array}{c}\text { IgG } \\
\text { Endpoint } \\
\text { Titer }\end{array}$ & PRNT50 \\
\hline 1 & Hospitalized & 1.54033 & 0.20517 & 1.62175 & 300 & 836.40623 \\
\hline 2 & Hospitalized & 0.74583 & 0.31517 & 2.85825 & 900 & 921.62114 \\
\hline 3 & Hospitalized & 0.67783 & 0.34317 & 0.47925 & 100 & $<256$ \\
\hline 4 & Hospitalized & 0.99933 & 0.27067 & 1.52375 & 300 & 258.98954 \\
\hline 5 & Hospitalized & 0.62183 & 0.22717 & 1.70475 & 900 & 1313.68166 \\
\hline 6 & Hospitalized & 0.68583 & 0.28917 & 1.06425 & 300 & 449.10221 \\
\hline 7 & Hospitalized & 0.78883 & 0.17217 & 0.71725 & 300 & 480.18948 \\
\hline 8 & Hospitalized & 0.88683 & 0.47967 & 0.71125 & 900 & 573.74664 \\
\hline 9 & Hospitalized & 1.61183 & 0.36017 & 2.57075 & 300 & 8476.12680 \\
\hline 10 & Hospitalized & 1.37233 & 0.43717 & 1.83525 & 900 & 1338.03487 \\
\hline 11 & Hospitalized & 0.45933 & 0.10267 & 1.05375 & 100 & 280.18774 \\
\hline 12 & Hospitalized & 2.73683 & 0.87467 & 1.89875 & 900 & 40379.72907 \\
\hline 13 & Hospitalized & 0.71533 & 0.33567 & 1.53775 & 900 & 4765.13047 \\
\hline 14 & Hospitalized & 0.78783 & 0.53117 & 1.42475 & 300 & 853.79742 \\
\hline 15 & Hospitalized & 2.11933 & 0.66317 & 2.15475 & 900 & 4224.60283 \\
\hline 16 & Hospitalized & 0.34633 & 0.20417 & 1.87675 & 2700 & 1844.73772 \\
\hline 17 & Hospitalized & 0.51233 & 0.44967 & 2.22425 & 900 & 1145.53038 \\
\hline 18 & Hospitalized & 0.44583 & 1.25017 & 2.38525 & 900 & 1213.15711 \\
\hline 19 & Hospitalized & 0.45033 & 0.19517 & 0.86775 & 300 & 430.68223 \\
\hline 20 & Hospitalized & 0.72133 & 0.13167 & 2.88325 & 8100 & 26949.80005 \\
\hline 21 & Hospitalized & 1.73183 & 0.65817 & 1.37975 & 900 & 26866.56566 \\
\hline 22 & Hospitalized & 0.54533 & 0.15967 & 0.83125 & 900 & 673.83894 \\
\hline 23 & Hospitalized & 0.73033 & 0.21467 & 1.06225 & 300 & 819.57377 \\
\hline 24 & Hospitalized & 1.12433 & 0.12850 & 0.90950 & 300 & 312.85492 \\
\hline
\end{tabular}




\begin{tabular}{|c|c|c|c|c|c|c|}
\hline 25 & Hospitalized & 1.81983 & 0.36550 & 2.12800 & 900 & 231.55482 \\
\hline 26 & Hospitalized & 1.27933 & 0.36850 & 1.15700 & 900 & 4746.34087 \\
\hline 27 & Hospitalized & 0.37933 & 0.20000 & 0.84050 & 300 & 1077.22209 \\
\hline 28 & Hospitalized & 0.62183 & 0.13450 & 1.58950 & 900 & 1048.74972 \\
\hline 29 & Hospitalized & 0.58283 & 0.15100 & 0.90850 & 300 & 576.34945 \\
\hline 30 & Hospitalized & 0.29483 & 0.27350 & 1.15950 & 900 & 274.88607 \\
\hline 31 & Hospitalized & 0.76933 & 0.42750 & 1.45700 & 900 & 16268.57199 \\
\hline 32 & Hospitalized & 0.99133 & 0.86100 & 1.79950 & 2700 & 4185.25555 \\
\hline 33 & Hospitalized & 0.78633 & 1.00400 & 1.97900 & 2700 & 9812.41159 \\
\hline 34 & Hospitalized & 1.25383 & 0.20550 & 1.59100 & 900 & 3625.58982 \\
\hline 35 & Hospitalized & 0.91933 & 0.23150 & 1.61700 & 900 & 52226.84076 \\
\hline 36 & Hospitalized & 1.02883 & 0.58600 & 0.98450 & 300 & 6135.64799 \\
\hline 37 & Hospitalized & 0.67833 & 0.62600 & 1.39550 & 300 & 2531.97299 \\
\hline 38 & Hospitalized & 2.46533 & 0.78300 & 1.50200 & 2700 & 37905.38126 \\
\hline 39 & Hospitalized & 0.44283 & 0.35050 & 1.58050 & 900 & 2326.58793 \\
\hline 40 & Hospitalized & 0.57633 & 0.39300 & 1.34600 & 900 & 8327.10904 \\
\hline 41 & Hospitalized & 0.52483 & 0.51450 & 1.19100 & 300 & 348.02328 \\
\hline 42 & Hospitalized & 1.62183 & 0.53500 & 1.46400 & 900 & 71725.57459 \\
\hline 43 & Hospitalized & 1.10733 & 0.83700 & 2.09450 & 8100 & 49766.67608 \\
\hline 44 & Hospitalized & 0.32883 & 0.05900 & 0.88100 & 300 & 2895.30577 \\
\hline 45 & Hospitalized & 1.01783 & 0.26150 & 1.59950 & 900 & 1562.99776 \\
\hline 46 & Hospitalized & 2.49483 & 0.85050 & 2.09500 & 8100 & 34344.03843 \\
\hline 47 & Non-Hospitalized & 1.03200 & 0.42150 & 1.26900 & 300 & $<256$ \\
\hline 48 & Non-Hospitalized & 0.71550 & 2.24600 & 2.75000 & 8100 & 2626.41000 \\
\hline 49 & Non-Hospitalized & 0.72300 & 0.56650 & 2.69050 & 8100 & 19542.41000 \\
\hline 50 & Non-Hospitalized & 1.15900 & 0.33300 & 0.80950 & 300 & 1584.83000 \\
\hline 51 & Non-Hospitalized & 1.31250 & 0.59550 & 2.13550 & 900 & $<256$ \\
\hline 52 & Non-Hospitalized & 0.34550 & 0.28500 & 1.51900 & 900 & 351.30000 \\
\hline
\end{tabular}




\begin{tabular}{|c|c|c|c|c|c|c|}
\hline 53 & Non-Hospitalized & 0.71500 & 0.14950 & 1.02700 & 300 & 615.55000 \\
\hline 54 & Non-Hospitalized & 0.50800 & -0.02700 & 1.12200 & 300 & 346.07000 \\
\hline 55 & Non-Hospitalized & 0.93750 & 0.44700 & 1.72650 & 900 & 379.42603 \\
\hline 56 & Non-Hospitalized & 2.20650 & 0.27450 & 1.59600 & 300 & 101.75949 \\
\hline 57 & Non-Hospitalized & 0.41100 & 0.58100 & 1.80150 & 900 & 1584.97230 \\
\hline 58 & Non-Hospitalized & 0.20900 & 1.57050 & 0.98150 & 300 & 780.43602 \\
\hline 59 & Non-Hospitalized & 0.14800 & 0.07250 & 0.90950 & 300 & $<256$ \\
\hline 60 & Non-Hospitalized & 1.26400 & 1.24950 & 1.74400 & 900 & 1226.90420 \\
\hline 61 & Non-Hospitalized & 0.55650 & 0.15600 & 1.04600 & 300 & $<256$ \\
\hline 62 & Non-Hospitalized & 2.30250 & 0.31550 & 1.62900 & 900 & 946.81037 \\
\hline 63 & Non-Hospitalized & 0.47300 & 0.14550 & 0.73350 & 100 & $<256$ \\
\hline 64 & Non-Hospitalized & 1.22950 & 0.18300 & 0.42800 & 100 & $<256$ \\
\hline 65 & Non-Hospitalized & 0.94050 & 0.28350 & 1.13600 & 300 & 13399.51000 \\
\hline 66 & Non-Hospitalized & 0.63950 & 0.36500 & 0.92400 & 300 & $<256$ \\
\hline 67 & Non-Hospitalized & 0.66650 & 0.20850 & 0.99800 & 300 & 637.86000 \\
\hline 68 & Non-Hospitalized & 0.88700 & 0.10400 & 0.81700 & 300 & Not Tested \\
\hline 69 & Non-Hospitalized & 0.36950 & 0.18350 & 0.35000 & $<100$ & Not Tested \\
\hline 70 & Non-Hospitalized & 1.04550 & 0.10200 & 0.95450 & 300 & Not Tested \\
\hline 71 & Non-Hospitalized & 0.33050 & $\mathbf{0 . 5 3 7 5 0}$ & 0.47550 & 100 & Not Tested \\
\hline 72 & Non-Hospitalized & 0.78850 & 0.17550 & 1.42300 & 900 & Not Tested \\
\hline 73 & Non-Hospitalized & 0.55600 & 0.18650 & 1.46750 & 900 & Not Tested \\
\hline 74 & Non-Hospitalized & 0.98800 & 0.41750 & 2.46150 & 24300 & Not Tested \\
\hline 75 & Non-Hospitalized & 0.23250 & 0.20950 & 1.15950 & 300 & Not Tested \\
\hline 76 & Non-Hospitalized & 0.34000 & 0.54300 & 1.55850 & 900 & Not Tested \\
\hline 77 & Non-Hospitalized & 0.56050 & 0.22650 & 0.78700 & 300 & Not Tested \\
\hline 78 & Non-Hospitalized & 0.39300 & 0.25300 & 0.29850 & $<100$ & Not Tested \\
\hline 79 & Non-Hospitalized & 0.27000 & 0.09250 & 1.46250 & 900 & Not Tested \\
\hline 80 & Non-Hospitalized & 1.36550 & 0.46000 & 1.00800 & 300 & Not Tested \\
\hline
\end{tabular}




\begin{tabular}{|c|c|c|c|c|c|c|}
\hline 81 & Non-Hospitalized & 0.19700 & 0.28450 & 0.88300 & 300 & Not Tested \\
\hline 82 & Non-Hospitalized & 0.44050 & 0.18850 & 1.19200 & 300 & Not Tested \\
\hline 83 & Negative & 0.13183 & 0.38567 & 0.29275 & Not Tested & Not Tested \\
\hline 84 & Negative & 0.16583 & 0.08667 & 0.09925 & Not Tested & Not Tested \\
\hline 85 & Negative & 0.19833 & 0.40217 & 0.19675 & Not Tested & Not Tested \\
\hline 86 & Negative & 0.12883 & 0.11017 & 0.14875 & Not Tested & Not Tested \\
\hline 87 & Negative & 1.19033 & 0.22567 & 0.30975 & Not Tested & Not Tested \\
\hline 88 & Negative & 0.04583 & 0.28267 & 0.17225 & Not Tested & Not Tested \\
\hline 89 & Negative & 0.23733 & 0.21867 & 0.13725 & Not Tested & Not Tested \\
\hline 90 & Negative & 0.41783 & 0.17917 & 0.09575 & Not Tested & Not Tested \\
\hline 91 & Negative & 0.17633 & 0.14067 & 0.30875 & Not Tested & Not Tested \\
\hline 92 & Negative & 0.19883 & 0.08117 & 0.27025 & Not Tested & Not Tested \\
\hline 93 & Negative & 0.22933 & 0.19067 & 0.15075 & Not Tested & Not Tested \\
\hline 94 & Negative & 0.14783 & 0.25117 & 0.12475 & Not Tested & Not Tested \\
\hline 95 & Negative & 0.14533 & 0.04817 & 0.20325 & Not Tested & Not Tested \\
\hline 96 & Negative & 1.06383 & 0.17917 & 0.58075 & Not Tested & Not Tested \\
\hline 97 & Negative & 0.62333 & 0.13267 & 0.12725 & Not Tested & Not Tested \\
\hline 98 & Negative & 0.85683 & 0.07167 & 0.08875 & Not Tested & Not Tested \\
\hline 99 & Negative & 1.59583 & 0.23267 & 0.36775 & Not Tested & Not Tested \\
\hline 100 & Negative & 0.20833 & 0.03267 & 0.10375 & Not Tested & Not Tested \\
\hline 101 & Negative & 0.26733 & 0.15717 & 0.14475 & Not Tested & Not Tested \\
\hline 102 & Negative & 0.93983 & 0.20517 & 0.31475 & Not Tested & Not Tested \\
\hline 103 & Negative & 0.17983 & 0.22367 & 0.14725 & Not Tested & Not Tested \\
\hline 104 & Negative & 0.53533 & 0.29917 & 0.17825 & Not Tested & Not Tested \\
\hline 105 & Negative & 0.42133 & 0.17467 & 0.25475 & Not Tested & Not Tested \\
\hline 106 & Negative & 0.28533 & 0.10450 & 0.78600 & Not Tested & Not Tested \\
\hline 107 & Negative & 0.96483 & 0.13000 & 0.31050 & Not Tested & Not Tested \\
\hline 108 & Negative & 0.53783 & 0.14100 & 0.32150 & Not Tested & Not Tested \\
\hline
\end{tabular}




\begin{tabular}{|c|c|c|c|c|c|c|}
\hline 109 & Negative & 0.52733 & 0.09200 & 0.29250 & Not Tested & Not Tested \\
\hline 110 & Negative & 0.16433 & 0.20400 & 0.71650 & Not Tested & Not Tested \\
\hline 111 & Negative & 0.06533 & 0.14350 & 0.22950 & Not Tested & Not Tested \\
\hline 112 & Negative & 0.11133 & 0.22650 & 1.02250 & Not Tested & Not Tested \\
\hline 113 & Negative & 0.09133 & 0.18500 & 0.23100 & Not Tested & Not Tested \\
\hline 114 & Negative & 0.34233 & 0.18650 & 0.26050 & Not Tested & Not Tested \\
\hline 115 & Negative & 0.43583 & 0.23450 & 0.19750 & Not Tested & Not Tested \\
\hline 116 & Negative & 0.03783 & -0.02150 & 0.27550 & Not Tested & Not Tested \\
\hline 117 & Negative & 0.16133 & 0.06500 & 0.26200 & Not Tested & Not Tested \\
\hline 118 & Negative & 0.10533 & 0.12150 & 0.29450 & Not Tested & Not Tested \\
\hline 119 & Negative & 0.26833 & 0.23950 & 1.17150 & Not Tested & Not Tested \\
\hline 120 & Negative & 0.17083 & 0.26950 & 0.49150 & Not Tested & Not Tested \\
\hline 121 & Negative & 0.26633 & 0.46150 & 0.73500 & Not Tested & Not Tested \\
\hline 122 & Negative & 0.16833 & 0.11200 & 0.30700 & Not Tested & Not Tested \\
\hline 123 & Negative & 0.49683 & 0.39250 & 0.50100 & Not Tested & Not Tested \\
\hline 124 & Negative & 0.40983 & 0.17700 & 0.26200 & Not Tested & Not Tested \\
\hline 125 & Negative & 0.26183 & 0.05500 & 0.19250 & Not Tested & Not Tested \\
\hline 126 & Negative & 0.09433 & 0.12500 & 0.64550 & Not Tested & Not Tested \\
\hline 127 & Negative & 1.36483 & 0.99450 & 0.76650 & Not Tested & Not Tested \\
\hline 128 & Negative & 0.11433 & 0.29100 & 0.24700 & Not Tested & Not Tested \\
\hline
\end{tabular}




\section{APPENDIX II - ROC CURVE DATA}

A. IgG Pivot Table with Sensitivity, Specificity, and False Positive Rate

\begin{tabular}{|c|c|c|c|c|c|}
\hline Optical Density (AU) & Diseased (Pos) & Healthy (Neg) & Sensitivity & Specificity & False Positive Rate \\
\hline 0.08875 & & 1 & 1 & $\mathbf{0}$ & 1 \\
\hline 0.09575 & & 1 & 1 & 0.0217391 & 0.97826087 \\
\hline 0.09925 & & 1 & 1 & 0.0434783 & 0.956521739 \\
\hline 0.10375 & & 1 & 1 & 0.0652174 & 0.934782609 \\
\hline 0.12475 & & 1 & 1 & 0.0869565 & 0.913043478 \\
\hline 0.12725 & & 1 & 1 & 0.1086957 & 0.891304348 \\
\hline 0.13725 & & 1 & 1 & 0.1304348 & 0.869565217 \\
\hline 0.14475 & & 1 & 1 & 0.1521739 & 0.847826087 \\
\hline 0.14725 & & 1 & 1 & 0.173913 & 0.826086957 \\
\hline 0.14875 & & 1 & 1 & 0.1956522 & 0.804347826 \\
\hline 0.15075 & & 1 & 1 & 0.2173913 & 0.782608696 \\
\hline 0.17225 & & 1 & 1 & 0.2391304 & 0.760869565 \\
\hline 0.17825 & & 1 & 1 & 0.2608696 & 0.739130435 \\
\hline 0.1925 & & 1 & 1 & 0.2826087 & 0.717391304 \\
\hline 0.19675 & & 1 & 1 & 0.3043478 & 0.695652174 \\
\hline 0.1975 & & 1 & 1 & 0.326087 & 0.673913043 \\
\hline 0.20325 & & 1 & 1 & 0.3478261 & 0.652173913 \\
\hline 0.2295 & & 1 & 1 & 0.3695652 & 0.630434783 \\
\hline 0.231 & & 1 & 1 & 0.3913043 & 0.608695652 \\
\hline 0.247 & & 1 & 1 & 0.4130435 & 0.586956522 \\
\hline 0.25475 & & 1 & 1 & 0.4347826 & 0.565217391 \\
\hline 0.2605 & & 1 & 1 & 0.4565217 & 0.543478261 \\
\hline 0.262 & & 2 & 1 & 0.4782609 & 0.52173913 \\
\hline 0.27025 & & 1 & 1 & 0.5217391 & 0.47826087 \\
\hline 0.2755 & & 1 & 1 & 0.5434783 & 0.456521739 \\
\hline
\end{tabular}




\begin{tabular}{|c|c|c|c|c|c|}
\hline 0.2925 & & 1 & 1 & 0.5652174 & 0.434782609 \\
\hline 0.29275 & & 1 & 1 & 0.5869565 & 0.413043478 \\
\hline 0.2945 & & 1 & 1 & 0.6086957 & 0.391304348 \\
\hline 0.2985 & 1 & & 1 & 0.6304348 & 0.369565217 \\
\hline 0.307 & & 1 & 0.98780488 & 0.6304348 & 0.369565217 \\
\hline 0.30875 & & 1 & 0.98780488 & 0.6521739 & 0.347826087 \\
\hline 0.30975 & & 1 & 0.98780488 & 0.673913 & 0.326086957 \\
\hline 0.3105 & & 1 & 0.98780488 & 0.6956522 & 0.304347826 \\
\hline 0.31475 & & 1 & 0.98780488 & 0.7173913 & 0.282608696 \\
\hline 0.3215 & & 1 & 0.98780488 & 0.7391304 & 0.260869565 \\
\hline 0.35 & 1 & & 0.98780488 & 0.7608696 & 0.239130435 \\
\hline 0.36775 & & 1 & 0.97560976 & 0.7608696 & 0.239130435 \\
\hline 0.428 & 1 & & 0.97560976 & 0.7826087 & 0.217391304 \\
\hline 0.4755 & 1 & & 0.96341463 & 0.7826087 & 0.217391304 \\
\hline 0.47925 & 1 & & 0.95121951 & 0.7826087 & 0.217391304 \\
\hline 0.4915 & & 1 & 0.93902439 & 0.7826087 & 0.217391304 \\
\hline 0.501 & & 1 & 0.93902439 & 0.8043478 & 0.195652174 \\
\hline 0.58075 & & 1 & 0.93902439 & 0.826087 & 0.173913043 \\
\hline 0.6455 & & 1 & 0.93902439 & 0.8478261 & 0.152173913 \\
\hline 0.71125 & 1 & & 0.93902439 & 0.8695652 & 0.130434783 \\
\hline 0.7165 & & 1 & 0.92682927 & 0.8695652 & 0.130434783 \\
\hline 0.71725 & 1 & & 0.92682927 & 0.8913043 & 0.108695652 \\
\hline 0.7335 & 1 & & 0.91463415 & 0.8913043 & 0.108695652 \\
\hline 0.735 & & 1 & 0.90243902 & 0.8913043 & 0.108695652 \\
\hline 0.7665 & & 1 & 0.90243902 & 0.9130435 & 0.086956522 \\
\hline 0.786 & & 1 & 0.90243902 & 0.9347826 & 0.065217391 \\
\hline 0.787 & 1 & & 0.90243902 & 0.9565217 & 0.043478261 \\
\hline 0.8095 & 1 & & 0.8902439 & 0.9565217 & 0.043478261 \\
\hline
\end{tabular}




\begin{tabular}{|c|c|c|c|c|c|}
\hline 0.817 & 1 & & 0.87804878 & 0.9565217 & 0.043478261 \\
\hline 0.83125 & 1 & & 0.86585366 & 0.9565217 & 0.043478261 \\
\hline 0.8405 & 1 & & 0.85365854 & 0.9565217 & 0.043478261 \\
\hline 0.86775 & 1 & & 0.84146341 & 0.9565217 & 0.043478261 \\
\hline 0.881 & 1 & & 0.82926829 & 0.9565217 & 0.043478261 \\
\hline 0.883 & 1 & & $\mathbf{0 . 8 1 7 0 7 3 1 7}$ & 0.9565217 & 0.043478261 \\
\hline 0.9085 & 1 & & 0.80487805 & 0.9565217 & 0.043478261 \\
\hline 0.9095 & 2 & & 0.79268293 & 0.9565217 & 0.043478261 \\
\hline 0.924 & 1 & & 0.76829268 & 0.9565217 & 0.043478261 \\
\hline 0.9545 & 1 & & 0.75609756 & 0.9565217 & 0.043478261 \\
\hline 0.9815 & 1 & & 0.74390244 & 0.9565217 & 0.043478261 \\
\hline 0.9845 & 1 & & 0.73170732 & 0.9565217 & 0.043478261 \\
\hline 0.998 & 1 & & 0.7195122 & 0.9565217 & 0.043478261 \\
\hline 1.008 & 1 & & $\mathbf{0 . 7 0 7 3 1 7 0 7}$ & 0.9565217 & 0.043478261 \\
\hline 1.0225 & & 1 & 0.69512195 & 0.9565217 & 0.043478261 \\
\hline 1.027 & 1 & & 0.69512195 & 0.9782609 & 0.02173913 \\
\hline 1.046 & 1 & & 0.68292683 & 0.9782609 & 0.02173913 \\
\hline 1.05375 & 1 & & 0.67073171 & 0.9782609 & 0.02173913 \\
\hline 1.06225 & 1 & & 0.65853659 & 0.9782609 & 0.02173913 \\
\hline 1.06425 & 1 & & 0.64634146 & 0.9782609 & 0.02173913 \\
\hline 1.122 & 1 & & 0.63414634 & 0.9782609 & 0.02173913 \\
\hline 1.136 & 1 & & 0.62195122 & 0.9782609 & 0.02173913 \\
\hline 1.157 & 1 & & 0.6097561 & 0.9782609 & 0.02173913 \\
\hline 1.1595 & 2 & & 0.59756098 & 0.9782609 & 0.02173913 \\
\hline 1.1715 & & 1 & 0.57317073 & 0.9782609 & 0.02173913 \\
\hline 1.191 & 1 & & 0.57317073 & 1 & $\mathbf{0}$ \\
\hline 1.192 & 1 & & 0.56097561 & 1 & $\mathbf{0}$ \\
\hline 1.269 & 1 & & 0.54878049 & 1 & $\mathbf{0}$ \\
\hline
\end{tabular}




\begin{tabular}{|c|c|c|c|c|}
\hline 1.346 & 1 & 0.53658537 & 1 & $\mathbf{0}$ \\
\hline 1.37975 & 1 & 0.52439024 & 1 & $\mathbf{0}$ \\
\hline 1.3955 & 1 & 0.51219512 & 1 & $\mathbf{0}$ \\
\hline 1.423 & 1 & 0.5 & 1 & $\mathbf{0}$ \\
\hline 1.42475 & 1 & 0.48780488 & 1 & $\mathbf{0}$ \\
\hline 1.457 & 1 & 0.47560976 & 1 & $\mathbf{0}$ \\
\hline 1.4625 & 1 & 0.46341463 & 1 & $\mathbf{0}$ \\
\hline 1.464 & 1 & 0.45121951 & 1 & $\mathbf{0}$ \\
\hline 1.4675 & 1 & 0.43902439 & 1 & $\mathbf{0}$ \\
\hline 1.502 & 1 & 0.42682927 & 1 & $\mathbf{0}$ \\
\hline 1.519 & 1 & 0.41463415 & 1 & $\mathbf{0}$ \\
\hline 1.52375 & 1 & 0.40243902 & 1 & $\mathbf{0}$ \\
\hline 1.53775 & 1 & 0.3902439 & 1 & $\mathbf{0}$ \\
\hline 1.5585 & 1 & 0.37804878 & 1 & $\mathbf{0}$ \\
\hline 1.5805 & 1 & 0.36585366 & 1 & $\mathbf{0}$ \\
\hline 1.5895 & 1 & 0.35365854 & 1 & $\mathbf{0}$ \\
\hline 1.591 & 1 & 0.34146341 & 1 & $\mathbf{0}$ \\
\hline 1.596 & 1 & 0.32926829 & 1 & $\mathbf{0}$ \\
\hline 1.5995 & 1 & 0.31707317 & 1 & $\mathbf{0}$ \\
\hline 1.617 & 1 & 0.30487805 & 1 & $\mathbf{0}$ \\
\hline 1.62175 & 1 & 0.29268293 & 1 & $\mathbf{0}$ \\
\hline 1.629 & 1 & 0.2804878 & 1 & $\mathbf{0}$ \\
\hline 1.70475 & 1 & 0.26829268 & 1 & $\mathbf{0}$ \\
\hline 1.7265 & 1 & 0.25609756 & 1 & $\mathbf{0}$ \\
\hline 1.744 & 1 & 0.24390244 & 1 & $\mathbf{0}$ \\
\hline 1.7995 & 1 & 0.23170732 & 1 & 0 \\
\hline 1.8015 & 1 & 0.2195122 & 1 & 0 \\
\hline 1.83525 & 1 & 0.20731707 & 1 & $\mathbf{0}$ \\
\hline
\end{tabular}




\begin{tabular}{|c|c|c|c|c|c|}
\hline 1.87675 & 1 & & 0.19512195 & 1 & $\mathbf{0}$ \\
\hline 1.89875 & 1 & & 0.18292683 & 1 & $\mathbf{0}$ \\
\hline 1.979 & 1 & & 0.17073171 & 1 & $\mathbf{0}$ \\
\hline 2.0945 & 1 & & 0.15853659 & 1 & $\mathbf{0}$ \\
\hline 2.095 & 1 & & 0.14634146 & 1 & $\mathbf{0}$ \\
\hline 2.128 & 1 & & 0.13414634 & 1 & $\mathbf{0}$ \\
\hline 2.1355 & 1 & & 0.12195122 & 1 & $\mathbf{0}$ \\
\hline 2.15475 & 1 & & 0.1097561 & 1 & $\mathbf{0}$ \\
\hline 2.22425 & 1 & & 0.09756098 & 1 & $\mathbf{0}$ \\
\hline 2.38525 & 1 & & 0.08536585 & 1 & $\mathbf{0}$ \\
\hline 2.4615 & 1 & & 0.07317073 & 1 & $\mathbf{0}$ \\
\hline 2.57075 & 1 & & 0.06097561 & 1 & $\mathbf{0}$ \\
\hline 2.6905 & 1 & & 0.04878049 & 1 & $\mathbf{0}$ \\
\hline 2.75 & 1 & & 0.03658537 & 1 & $\mathbf{0}$ \\
\hline 2.85825 & 1 & & 0.02439024 & 1 & $\mathbf{0}$ \\
\hline 2.88325 & 1 & & 0.01219512 & 1 & $\mathbf{0}$ \\
\hline Grand Total & 82 & 46 & & & \\
\hline
\end{tabular}

B. IgA Pivot Table with Sensitivity, Specificity, and False Positive Rate

\section{\begin{tabular}{|l|lll|ll} 
Optical Density (AU) & Diseased (Pos) & Healthy (Neg) & Sensitivity & Specificity & False Positive Rate
\end{tabular}}

\begin{tabular}{|c|c|c|c|c|c|}
\hline-0.027 & 1 & & 1 & 0 & 1 \\
\hline-0.0215 & & 1 & 0.98780488 & 0 & 1 \\
\hline 0.032666667 & & 1 & 0.98780488 & 0.0217391 & 0.97826087 \\
\hline 0.048166667 & & 1 & 0.98780488 & 0.0434783 & 0.956521739 \\
\hline 0.055 & & 1 & 0.98780488 & 0.0652174 & 0.934782609 \\
\hline 0.059 & 1 & & 0.98780488 & 0.0869565 & 0.913043478 \\
\hline 0.065 & & 1 & 0.97560976 & 0.0869565 & 0.913043478 \\
\hline 0.071666667 & & 1 & 0.97560976 & 0.1086957 & 0.891304348 \\
\hline
\end{tabular}




\begin{tabular}{|c|c|c|c|c|c|}
\hline 0.0725 & 1 & & 0.97560976 & 0.1304348 & 0.869565217 \\
\hline 0.081166667 & & 1 & 0.96341463 & 0.1304348 & 0.869565217 \\
\hline 0.086666667 & & 1 & 0.96341463 & 0.1521739 & 0.847826087 \\
\hline 0.092 & & 1 & 0.96341463 & 0.173913 & 0.826086957 \\
\hline 0.0925 & 1 & & 0.96341463 & 0.1956522 & 0.804347826 \\
\hline 0.102 & 1 & & 0.95121951 & 0.1956522 & 0.804347826 \\
\hline 0.102666667 & 1 & & 0.93902439 & 0.1956522 & 0.804347826 \\
\hline 0.104 & 1 & & 0.92682927 & 0.1956522 & 0.804347826 \\
\hline 0.1045 & & 1 & 0.91463415 & 0.1956522 & 0.804347826 \\
\hline 0.110166667 & & 1 & 0.91463415 & 0.2173913 & 0.782608696 \\
\hline 0.112 & & 1 & 0.91463415 & 0.2391304 & 0.760869565 \\
\hline 0.1215 & & 1 & 0.91463415 & 0.2608696 & 0.739130435 \\
\hline 0.125 & & 1 & 0.91463415 & 0.2826087 & 0.717391304 \\
\hline 0.1285 & 1 & & 0.91463415 & 0.3043478 & 0.695652174 \\
\hline 0.13 & & 1 & 0.90243902 & 0.3043478 & 0.695652174 \\
\hline 0.131666667 & 1 & & 0.90243902 & 0.326087 & 0.673913043 \\
\hline 0.132666667 & & 1 & 0.8902439 & 0.326087 & 0.673913043 \\
\hline 0.1345 & 1 & & 0.8902439 & 0.3478261 & 0.652173913 \\
\hline 0.140666667 & & 1 & 0.87804878 & 0.3478261 & 0.652173913 \\
\hline 0.141 & & 1 & 0.87804878 & 0.3695652 & 0.630434783 \\
\hline 0.1435 & & 1 & 0.87804878 & 0.3913043 & 0.608695652 \\
\hline 0.1455 & 1 & & 0.87804878 & 0.4130435 & 0.586956522 \\
\hline 0.1495 & 1 & & 0.86585366 & 0.4130435 & 0.586956522 \\
\hline 0.151 & 1 & & 0.85365854 & 0.4130435 & 0.586956522 \\
\hline 0.156 & 1 & & 0.84146341 & 0.4130435 & 0.586956522 \\
\hline 0.157166667 & & 1 & 0.82926829 & 0.4130435 & 0.586956522 \\
\hline 0.159666667 & 1 & & 0.82926829 & 0.4347826 & 0.565217391 \\
\hline 0.172166667 & 1 & & 0.81707317 & 0.4347826 & 0.565217391 \\
\hline
\end{tabular}




\begin{tabular}{|c|c|c|c|c|c|}
\hline 0.174666667 & & 1 & 0.80487805 & 0.4347826 & 0.565217391 \\
\hline 0.1755 & 1 & & 0.80487805 & 0.4565217 & 0.543478261 \\
\hline 0.177 & & 1 & 0.79268293 & 0.4565217 & 0.543478261 \\
\hline 0.179166667 & & 2 & 0.79268293 & 0.4782609 & 0.52173913 \\
\hline 0.183 & 1 & & 0.79268293 & 0.5217391 & 0.47826087 \\
\hline 0.1835 & 1 & & 0.7804878 & 0.5217391 & 0.47826087 \\
\hline 0.185 & & 1 & 0.76829268 & 0.5217391 & 0.47826087 \\
\hline 0.1865 & 1 & 1 & 0.76829268 & 0.5434783 & 0.456521739 \\
\hline 0.1885 & 1 & & 0.75609756 & 0.5652174 & 0.434782609 \\
\hline 0.190666667 & & 1 & 0.74390244 & 0.5652174 & 0.434782609 \\
\hline 0.195166667 & 1 & & 0.74390244 & 0.5869565 & 0.413043478 \\
\hline 0.2 & 1 & & 0.73170732 & 0.5869565 & 0.413043478 \\
\hline 0.204 & & 1 & 0.7195122 & 0.5869565 & 0.413043478 \\
\hline 0.204166667 & 1 & & 0.7195122 & 0.6086957 & 0.391304348 \\
\hline 0.205166667 & 1 & & 0.70731707 & 0.6086957 & 0.391304348 \\
\hline 0.205166667 & & 1 & 0.69512195 & 0.6086957 & 0.391304348 \\
\hline 0.2055 & 1 & & 0.69512195 & 0.6304348 & 0.369565217 \\
\hline 0.2085 & 1 & & 0.68292683 & 0.6304348 & 0.369565217 \\
\hline 0.2095 & 1 & & 0.67073171 & 0.6304348 & 0.369565217 \\
\hline 0.214666667 & 1 & & 0.65853659 & 0.6304348 & 0.369565217 \\
\hline 0.218666667 & & 1 & 0.64634146 & 0.6304348 & 0.369565217 \\
\hline 0.223666667 & & 1 & 0.64634146 & 0.6521739 & 0.347826087 \\
\hline 0.225666667 & & 1 & 0.64634146 & 0.673913 & 0.326086957 \\
\hline 0.2265 & & 1 & 0.64634146 & 0.6956522 & 0.304347826 \\
\hline 0.2265 & 1 & & 0.64634146 & 0.7173913 & 0.282608696 \\
\hline 0.227166667 & 1 & & 0.63414634 & 0.7173913 & 0.282608696 \\
\hline 0.2315 & 1 & & 0.62195122 & 0.7173913 & 0.282608696 \\
\hline 0.232666667 & & 1 & 0.6097561 & 0.7173913 & 0.282608696 \\
\hline
\end{tabular}




\begin{tabular}{|c|c|c|c|c|c|}
\hline 0.2345 & & 1 & 0.6097561 & 0.7391304 & 0.260869565 \\
\hline 0.2395 & & 1 & 0.6097561 & 0.7608696 & 0.239130435 \\
\hline 0.251166667 & & 1 & 0.6097561 & 0.7826087 & 0.217391304 \\
\hline 0.253 & 1 & & 0.6097561 & 0.8043478 & 0.195652174 \\
\hline 0.2615 & 1 & & 0.59756098 & 0.8043478 & 0.195652174 \\
\hline 0.2695 & & 1 & 0.58536585 & 0.8043478 & 0.195652174 \\
\hline 0.270666667 & 1 & & 0.58536585 & 0.826087 & 0.173913043 \\
\hline 0.2735 & 1 & & 0.57317073 & 0.826087 & 0.173913043 \\
\hline 0.2745 & 1 & & 0.56097561 & 0.826087 & 0.173913043 \\
\hline 0.282666667 & & 1 & 0.54878049 & 0.826087 & 0.173913043 \\
\hline 0.2835 & 1 & & 0.54878049 & 0.8478261 & 0.152173913 \\
\hline 0.2845 & 1 & & 0.53658537 & 0.8478261 & 0.152173913 \\
\hline 0.285 & 1 & & 0.52439024 & 0.8478261 & 0.152173913 \\
\hline 0.289166667 & 1 & & 0.51219512 & 0.8478261 & 0.152173913 \\
\hline 0.291 & & 1 & 0.5 & 0.8478261 & 0.152173913 \\
\hline 0.299166667 & & 1 & 0.5 & 0.8695652 & 0.130434783 \\
\hline 0.315166667 & 1 & & 0.5 & 0.8913043 & 0.108695652 \\
\hline 0.3155 & 1 & & 0.48780488 & 0.8913043 & 0.108695652 \\
\hline 0.333 & 1 & & 0.47560976 & 0.8913043 & 0.108695652 \\
\hline 0.335666667 & 1 & & 0.46341463 & 0.8913043 & 0.108695652 \\
\hline 0.343166667 & 1 & & 0.45121951 & 0.8913043 & 0.108695652 \\
\hline 0.3505 & 1 & & 0.43902439 & 0.8913043 & 0.108695652 \\
\hline 0.360166667 & 1 & & 0.42682927 & 0.8913043 & 0.108695652 \\
\hline 0.365 & 1 & & 0.41463415 & 0.8913043 & 0.108695652 \\
\hline 0.3655 & 1 & & 0.40243902 & 0.8913043 & 0.108695652 \\
\hline 0.3685 & 1 & & 0.3902439 & 0.8913043 & 0.108695652 \\
\hline 0.385666667 & & 1 & 0.37804878 & 0.8913043 & 0.108695652 \\
\hline 0.3925 & & 1 & 0.37804878 & 0.9130435 & 0.086956522 \\
\hline
\end{tabular}




\begin{tabular}{|c|c|c|c|c|c|}
\hline 0.393 & 1 & & 0.37804878 & 0.9347826 & 0.065217391 \\
\hline 0.402166667 & & 1 & 0.36585366 & 0.9347826 & 0.065217391 \\
\hline 0.4175 & 1 & & 0.36585366 & 0.9565217 & 0.043478261 \\
\hline 0.4215 & 1 & & 0.35365854 & 0.9565217 & 0.043478261 \\
\hline 0.4275 & 1 & & 0.34146341 & 0.9565217 & 0.043478261 \\
\hline 0.437166667 & 1 & & 0.32926829 & 0.9565217 & 0.043478261 \\
\hline 0.447 & 1 & & 0.31707317 & 0.9565217 & 0.043478261 \\
\hline 0.449666667 & 1 & & 0.30487805 & 0.9565217 & 0.043478261 \\
\hline 0.46 & 1 & & 0.29268293 & 0.9565217 & 0.043478261 \\
\hline 0.4615 & & 1 & 0.2804878 & 0.9565217 & 0.043478261 \\
\hline 0.479666667 & 1 & & 0.2804878 & 0.9782609 & 0.02173913 \\
\hline 0.5145 & 1 & & 0.26829268 & 0.9782609 & 0.02173913 \\
\hline 0.531166667 & 1 & & 0.25609756 & 0.9782609 & 0.02173913 \\
\hline 0.535 & 1 & & 0.24390244 & 0.9782609 & 0.02173913 \\
\hline 0.5375 & 1 & & 0.23170732 & 0.9782609 & 0.02173913 \\
\hline 0.543 & 1 & & 0.2195122 & 0.9782609 & 0.02173913 \\
\hline 0.5665 & 1 & & 0.20731707 & 0.9782609 & 0.02173913 \\
\hline 0.581 & 1 & & 0.19512195 & 0.9782609 & 0.02173913 \\
\hline 0.586 & 1 & & 0.18292683 & 0.9782609 & 0.02173913 \\
\hline 0.5955 & 1 & & 0.17073171 & 0.9782609 & 0.02173913 \\
\hline 0.626 & 1 & & 0.15853659 & 0.9782609 & 0.02173913 \\
\hline 0.658166667 & 1 & & 0.14634146 & 0.9782609 & 0.02173913 \\
\hline 0.663166667 & 1 & & 0.13414634 & 0.9782609 & 0.02173913 \\
\hline 0.783 & 1 & & 0.12195122 & 0.9782609 & 0.02173913 \\
\hline 0.837 & 1 & & 0.1097561 & 0.9782609 & 0.02173913 \\
\hline 0.8505 & 1 & & 0.09756098 & 0.9782609 & 0.02173913 \\
\hline 0.861 & 1 & & 0.08536585 & 0.9782609 & 0.02173913 \\
\hline 0.874666667 & 1 & & 0.07317073 & 0.9782609 & 0.02173913 \\
\hline
\end{tabular}




\begin{tabular}{|c|c|c|c|c|c|}
\hline 0.9945 & & 1 & 0.06097561 & 0.9782609 & 0.02173913 \\
\hline 1.004 & 1 & & 0.06097561 & 1 & 0 \\
\hline 1.2495 & 1 & & 0.04878049 & 1 & 0 \\
\hline 1.250166667 & 1 & & 0.03658537 & 1 & 0 \\
\hline 1.5705 & 1 & & 0.02439024 & 1 & 0 \\
\hline 2.246 & 82 & 46 & 0.01219512 & 1 & 0 \\
\hline
\end{tabular}

C. IgM Pivot Table with Sensitivity, Specificity, and False Positive Rate

\begin{tabular}{|c|c|c|c|c|c|}
\hline Optical Density (AU) & Diseased (Pos) & Healthy (Neg) & Sensitivity & Specificity & False Positive Rate \\
\hline 0.037833333 & & 1 & 1 & $\mathbf{0}$ & 1 \\
\hline 0.045833333 & & 1 & 1 & 0.0217391 & 0.97826087 \\
\hline 0.065333333 & & 1 & 1 & 0.0434783 & 0.956521739 \\
\hline 0.091333333 & & 1 & 1 & 0.0652174 & 0.934782609 \\
\hline 0.094333333 & & 1 & 1 & 0.0869565 & 0.913043478 \\
\hline 0.105333333 & & 1 & 1 & 0.1086957 & 0.891304348 \\
\hline 0.111333333 & & 1 & 1 & 0.1304348 & 0.869565217 \\
\hline 0.114333333 & & 1 & 1 & 0.1521739 & 0.847826087 \\
\hline 0.128833333 & & 1 & 1 & 0.173913 & 0.826086957 \\
\hline 0.131833333 & & 1 & 1 & 0.1956522 & 0.804347826 \\
\hline 0.145333333 & & 1 & 1 & 0.2173913 & 0.782608696 \\
\hline 0.147833333 & & 1 & 1 & 0.2391304 & 0.760869565 \\
\hline 0.148 & 1 & & 1 & 0.2608696 & 0.739130435 \\
\hline 0.161333333 & & 1 & 0.98780488 & 0.2608696 & 0.739130435 \\
\hline 0.164333333 & & 1 & 0.98780488 & 0.2826087 & 0.717391304 \\
\hline 0.165833333 & & 1 & 0.98780488 & 0.3043478 & 0.695652174 \\
\hline 0.168333333 & & 1 & 0.98780488 & 0.326087 & 0.673913043 \\
\hline 0.170833333 & & 1 & 0.98780488 & 0.3478261 & 0.652173913 \\
\hline
\end{tabular}




\begin{tabular}{|c|c|c|c|c|c|}
\hline 0.176333333 & & 1 & 0.98780488 & 0.3695652 & 0.630434783 \\
\hline 0.179833333 & & 1 & 0.98780488 & 0.3913043 & 0.608695652 \\
\hline 0.197 & 1 & & 0.98780488 & 0.4130435 & 0.586956522 \\
\hline 0.198333333 & & 1 & 0.97560976 & 0.4130435 & 0.586956522 \\
\hline 0.198833333 & & 1 & 0.97560976 & 0.4347826 & 0.565217391 \\
\hline 0.208333333 & & 1 & 0.97560976 & 0.4565217 & 0.543478261 \\
\hline 0.209 & 1 & & 0.97560976 & 0.4782609 & 0.52173913 \\
\hline 0.229333333 & & 1 & 0.96341463 & 0.4782609 & 0.52173913 \\
\hline 0.2325 & 1 & & 0.96341463 & 0.5 & 0.5 \\
\hline 0.237333333 & & 1 & 0.95121951 & 0.5 & 0.5 \\
\hline 0.261833333 & & 1 & 0.95121951 & 0.5217391 & 0.47826087 \\
\hline 0.266333333 & & 1 & 0.95121951 & 0.5434783 & 0.456521739 \\
\hline 0.267333333 & & 1 & 0.95121951 & 0.5652174 & 0.434782609 \\
\hline 0.268333333 & & 1 & 0.95121951 & 0.5869565 & 0.413043478 \\
\hline 0.27 & 1 & & 0.95121951 & 0.6086957 & 0.391304348 \\
\hline 0.285333333 & & 1 & 0.93902439 & 0.6086957 & 0.391304348 \\
\hline 0.294833333 & 1 & & 0.93902439 & 0.6304348 & 0.369565217 \\
\hline 0.328833333 & 1 & & 0.92682927 & 0.6304348 & 0.369565217 \\
\hline 0.3305 & 1 & & 0.91463415 & 0.6304348 & 0.369565217 \\
\hline 0.34 & 1 & & 0.90243902 & 0.6304348 & 0.369565217 \\
\hline 0.342333333 & & 1 & 0.8902439 & 0.6304348 & 0.369565217 \\
\hline 0.3455 & 1 & & 0.8902439 & 0.6521739 & 0.347826087 \\
\hline 0.346333333 & 1 & & 0.87804878 & 0.6521739 & 0.347826087 \\
\hline 0.3695 & 1 & & 0.86585366 & 0.6521739 & 0.347826087 \\
\hline 0.379333333 & 1 & & 0.85365854 & 0.6521739 & 0.347826087 \\
\hline 0.393 & 1 & & 0.84146341 & 0.6521739 & 0.347826087 \\
\hline 0.409833333 & & 1 & 0.82926829 & 0.6521739 & 0.347826087 \\
\hline 0.411 & 1 & & 0.82926829 & 0.673913 & 0.326086957 \\
\hline
\end{tabular}




\begin{tabular}{|c|c|c|c|c|c|}
\hline 0.417833333 & & 1 & 0.81707317 & 0.673913 & 0.326086957 \\
\hline 0.421333333 & & 1 & 0.81707317 & 0.6956522 & 0.304347826 \\
\hline 0.435833333 & & 1 & 0.81707317 & 0.7173913 & 0.282608696 \\
\hline 0.4405 & 1 & & 0.81707317 & 0.7391304 & 0.260869565 \\
\hline 0.442833333 & 1 & & 0.80487805 & 0.7391304 & 0.260869565 \\
\hline 0.445833333 & 1 & & 0.79268293 & 0.7391304 & 0.260869565 \\
\hline 0.450333333 & 1 & & 0.7804878 & 0.7391304 & 0.260869565 \\
\hline 0.459333333 & 1 & & 0.76829268 & 0.7391304 & 0.260869565 \\
\hline 0.473 & 1 & & 0.75609756 & 0.7391304 & 0.260869565 \\
\hline 0.496833333 & & 1 & 0.74390244 & 0.7391304 & 0.260869565 \\
\hline 0.508 & 1 & & 0.74390244 & 0.7608696 & 0.239130435 \\
\hline 0.512333333 & 1 & & 0.73170732 & 0.7608696 & 0.239130435 \\
\hline 0.524833333 & 1 & & 0.7195122 & 0.7608696 & 0.239130435 \\
\hline 0.527333333 & & 1 & 0.70731707 & 0.7608696 & 0.239130435 \\
\hline 0.535333333 & & 1 & 0.70731707 & 0.7826087 & 0.217391304 \\
\hline 0.537833333 & & 1 & 0.70731707 & 0.8043478 & 0.195652174 \\
\hline 0.545333333 & 1 & & 0.70731707 & 0.826087 & 0.173913043 \\
\hline 0.556 & 1 & & 0.69512195 & 0.826087 & 0.173913043 \\
\hline 0.5565 & 1 & & 0.68292683 & 0.826087 & 0.173913043 \\
\hline 0.5605 & 1 & & 0.67073171 & 0.826087 & 0.173913043 \\
\hline 0.576333333 & 1 & & 0.65853659 & 0.826087 & 0.173913043 \\
\hline 0.582833333 & 1 & & 0.64634146 & 0.826087 & 0.173913043 \\
\hline 0.621833333 & 2 & & 0.63414634 & 0.826087 & 0.173913043 \\
\hline 0.623333333 & & 1 & 0.6097561 & 0.826087 & 0.173913043 \\
\hline 0.6395 & 1 & & 0.6097561 & 0.8478261 & 0.152173913 \\
\hline 0.6665 & 1 & & 0.59756098 & 0.8478261 & 0.152173913 \\
\hline 0.677833333 & 1 & & 0.58536585 & 0.8478261 & 0.152173913 \\
\hline 0.678333333 & 1 & & 0.57317073 & 0.8478261 & 0.152173913 \\
\hline
\end{tabular}




\begin{tabular}{|c|c|c|c|c|c|}
\hline 0.685833333 & 1 & & 0.56097561 & 0.8478261 & 0.152173913 \\
\hline 0.715 & 1 & & 0.54878049 & 0.8478261 & 0.152173913 \\
\hline 0.715333333 & 1 & & $\mathbf{0 . 5 3 6 5 8 5 3 7}$ & 0.8478261 & 0.152173913 \\
\hline 0.7155 & 1 & & 0.52439024 & 0.8478261 & 0.152173913 \\
\hline 0.721333333 & 1 & & 0.51219512 & 0.8478261 & 0.152173913 \\
\hline 0.723 & 1 & & 0.5 & 0.8478261 & 0.152173913 \\
\hline 0.730333333 & 1 & & 0.48780488 & 0.8478261 & 0.152173913 \\
\hline 0.745833333 & 1 & & 0.47560976 & 0.8478261 & 0.152173913 \\
\hline 0.769333333 & 1 & & 0.46341463 & 0.8478261 & 0.152173913 \\
\hline 0.786333333 & 1 & & 0.45121951 & 0.8478261 & 0.152173913 \\
\hline 0.787833333 & 1 & & 0.43902439 & 0.8478261 & 0.152173913 \\
\hline 0.7885 & 1 & & 0.42682927 & 0.8478261 & 0.152173913 \\
\hline $\mathbf{0 . 7 8 8 8 3 3 3 3 3}$ & 1 & & 0.41463415 & 0.8478261 & 0.152173913 \\
\hline $\mathbf{0 . 8 5 6 8 3 3 3 3 3}$ & & 1 & 0.40243902 & 0.8478261 & 0.152173913 \\
\hline 0.886833333 & 1 & & 0.40243902 & 0.8695652 & 0.130434783 \\
\hline 0.887 & 1 & & 0.3902439 & 0.8695652 & 0.130434783 \\
\hline $\mathbf{0 . 9 1 9 3 3 3 3 3 3}$ & 1 & & 0.37804878 & 0.8695652 & $\mathbf{0 . 1 3 0 4 3 4 7 8 3}$ \\
\hline 0.9375 & 1 & & 0.36585366 & 0.8695652 & 0.130434783 \\
\hline 0.939833333 & & 1 & 0.35365854 & 0.8695652 & 0.130434783 \\
\hline 0.9405 & 1 & & 0.35365854 & 0.8913043 & 0.108695652 \\
\hline 0.964833333 & & 1 & 0.34146341 & 0.8913043 & 0.108695652 \\
\hline 0.988 & 1 & & 0.34146341 & 0.9130435 & 0.086956522 \\
\hline 0.991333333 & 1 & & 0.32926829 & 0.9130435 & 0.086956522 \\
\hline 0.999333333 & 1 & & 0.31707317 & 0.9130435 & 0.086956522 \\
\hline 1.017833333 & 1 & & 0.30487805 & 0.9130435 & 0.086956522 \\
\hline 1.028833333 & 1 & & 0.29268293 & 0.9130435 & 0.086956522 \\
\hline 1.032 & 1 & & 0.2804878 & 0.9130435 & 0.086956522 \\
\hline 1.0455 & 1 & & 0.26829268 & 0.9130435 & 0.086956522 \\
\hline
\end{tabular}




\begin{tabular}{|c|c|c|c|c|c|}
\hline 1.063833333 & & 1 & 0.25609756 & 0.9130435 & 0.086956522 \\
\hline 1.107333333 & 1 & & 0.25609756 & 0.9347826 & 0.065217391 \\
\hline 1.124333333 & 1 & & 0.24390244 & 0.9347826 & 0.065217391 \\
\hline 1.159 & 1 & & 0.23170732 & 0.9347826 & 0.065217391 \\
\hline 1.190333333 & & 1 & 0.2195122 & 0.9347826 & 0.065217391 \\
\hline 1.2295 & 1 & & 0.2195122 & 0.9565217 & 0.043478261 \\
\hline 1.253833333 & 1 & & 0.20731707 & 0.9565217 & 0.043478261 \\
\hline 1.264 & 1 & & 0.19512195 & 0.9565217 & 0.043478261 \\
\hline 1.279333333 & 1 & & 0.18292683 & 0.9565217 & 0.043478261 \\
\hline 1.3125 & 1 & & 0.17073171 & 0.9565217 & 0.043478261 \\
\hline 1.364833333 & & 1 & 0.15853659 & 0.9565217 & 0.043478261 \\
\hline 1.3655 & 1 & & 0.15853659 & 0.9782609 & 0.02173913 \\
\hline 1.372333333 & 1 & & 0.14634146 & 0.9782609 & 0.02173913 \\
\hline 1.540333333 & 1 & & 0.13414634 & 0.9782609 & 0.02173913 \\
\hline 1.595833333 & & 1 & 0.12195122 & 0.9782609 & 0.02173913 \\
\hline 1.611833333 & 1 & & 0.12195122 & 1 & $\mathbf{0}$ \\
\hline 1.621833333 & 1 & & 0.1097561 & 1 & $\mathbf{0}$ \\
\hline 1.731833333 & 1 & & 0.09756098 & 1 & $\mathbf{0}$ \\
\hline 1.819833333 & 1 & & 0.08536585 & 1 & $\mathbf{0}$ \\
\hline 2.119333333 & 1 & & 0.07317073 & 1 & $\mathbf{0}$ \\
\hline 2.2065 & 1 & & 0.06097561 & 1 & $\mathbf{0}$ \\
\hline 2.3025 & 1 & & 0.04878049 & 1 & $\mathbf{0}$ \\
\hline 2.465333333 & 1 & & 0.03658537 & 1 & $\mathbf{0}$ \\
\hline 2.494833333 & 1 & & 0.02439024 & 1 & $\mathbf{0}$ \\
\hline 2.736833333 & 1 & & 0.01219512 & 1 & $\mathbf{0}$ \\
\hline Grand Total & 82 & 46 & & & \\
\hline
\end{tabular}




\section{REFERENCES}

Astuti, I., \& Ysrafil. (2020). Severe Acute Respiratory Syndrome Coronavirus 2 (SARSCoV-2): An overview of viral structure and host response. Diabetes Metab Syndr, 14(4), 407-412. doi:10.1016/j.dsx.2020.04.020

Bader, M., Turner, A. J., \& Alenina, N. (2020). ACE2, a multifunctional protein - from cardiovascular regulation to COVID-19. Clin Sci (Lond), 134(23), 3229-3232. doi:10.1042/CS20201493

Bouwman, K. M., Tomris, I., Turner, H. L., van der Woude, R., Shamorkina, T. M., Bosman, G. P., . . . de Vries, R. P. (2021). Multimerization- and glycosylationdependent receptor binding of SARS-CoV-2 spike proteins. PLoS Pathog, 17(2), e1009282. doi:10.1371/journal.ppat.1009282

Bustin, S. A., \& Mueller, R. (2005). Real-time reverse transcription PCR (qRT-PCR) and its potential use in clinical diagnosis. Clin Sci (Lond), 109(4), 365-379. doi:10.1042/CS20050086

Chaung, J., Chan, D., Pada, S., \& Tambyah, P. A. (2020). Coinfection with COVID-19 and coronavirus HKU1-The critical need for repeat testing if clinically indicated. J Med Virol, 92(10), 1785-1786. doi:10.1002/jmv.25890

Chen, X., Lu, L., Qi, Z., Lu, H., Wang, J., Yu, X., . . Jiang, S. (2010). Novel recombinant engineered gp41 N-terminal heptad repeat trimers and their potential as anti-HIV-1 therapeutics or microbicides. J Biol Chem, 285(33), 25506-25515. doi:10.1074/jbc.M110.101170

Cinquanta, L., Fontana, D. E., \& Bizzaro, N. (2017). Chemiluminescent immunoassay technology: what does it change in autoantibody detection? Auto Immun Highlights, 8(1), 9. doi:10.1007/s13317-017-0097-2

Corman, J. M., Hamorsky, K. T., Shepherd, J. W., Hiatt, E., Fuqua, J. L., \& Palmer, K. E. (2020). Stability of plasmid and viral banks supporting the cGMP manufacture of Q-Griffithsin from a TMV-based viral vector. J Biotechnol, 320, 74-76. doi:10.1016/j.jbiotec.2020.06.009

Coronaviridae Study Group of the International Committee on Taxonomy of, V. (2020). The species Severe acute respiratory syndrome-related coronavirus: classifying 2019-nCoV and naming it SARS-CoV-2. Nat Microbiol, 5(4), 536-544. doi:10.1038/s41564-020-0695-z

Coste, A. T., Jaton, K., Papadimitriou-Olivgeris, M., Greub, G., \& Croxatto, A. (2021). Comparison of SARS-CoV-2 serological tests with different antigen targets. $J$ Clin Virol, 134, 104690. doi:10.1016/j.jcv.2020.104690

Flamholz, A. I., Prywes, N., Moran, U., Davidi, D., Bar-On, Y. M., Oltrogge, L. M., . . . Milo, R. (2019). Revisiting Trade-offs between Rubisco Kinetic Parameters. Biochemistry, 58(31), 3365-3376. doi:10.1021/acs.biochem.9b00237

Frank, S., Kammerer, R. A., Mechling, D., Schulthess, T., Landwehr, R., Bann, J., . . . Engel, J. (2001). Stabilization of short collagen-like triple helices by protein engineering. J Mol Biol, 308(5), 1081-1089. doi:10.1006/jmbi.2001.4644

Guo, Y. R., Cao, Q. D., Hong, Z. S., Tan, Y. Y., Chen, S. D., Jin, H. J., . . Yan, Y. (2020). The origin, transmission and clinical therapies on coronavirus disease 
2019 (COVID-19) outbreak - an update on the status. Mil Med Res, 7(1), 11. doi:10.1186/s40779-020-00240-0

Hamming, I., Timens, W., Bulthuis, M. L., Lely, A. T., Navis, G., \& van Goor, H. (2004). Tissue distribution of ACE2 protein, the functional receptor for SARS coronavirus. A first step in understanding SARS pathogenesis. J Pathol, 203(2), 631-637. doi:10.1002/path.1570

Huang, Y., Yang, C., Xu, X. F., Xu, W., \& Liu, S. W. (2020). Structural and functional properties of SARS-CoV-2 spike protein: potential antivirus drug development for COVID-19. Acta Pharmacol Sin, 41(9), 1141-1149. doi:10.1038/s41401-0200485-4

Koczula, K. M., \& Gallotta, A. (2016). Lateral flow assays. Essays Biochem, 60(1), 111120. doi:10.1042/EBC20150012

Kowalczuk, S., Broer, A., Tietze, N., Vanslambrouck, J. M., Rasko, J. E., \& Broer, S. (2008). A protein complex in the brush-border membrane explains a Hartnup disorder allele. FASEB J, 22(8), 2880-2887. doi:10.1096/fj.08-107300

Kutti-Sridharan, G., Vegunta, R., Vegunta, R., Mohan, B. P., \& Rokkam, V. R. P. (2020). SARS-CoV2 in Different Body Fluids, Risks of Transmission, and Preventing COVID-19: A Comprehensive Evidence-Based Review. Int J Prev Med, 11, 97. doi:10.4103/ijpvm.IJPVM_255_20

Lee, C. Y., Lin, R. T. P., Renia, L., \& Ng, L. F. P. (2020). Serological Approaches for COVID-19: Epidemiologic Perspective on Surveillance and Control. Front Immunol, 11, 879. doi:10.3389/fimmu.2020.00879

Letarov, A. V., Londer, Y. Y., Boudko, S. P., \& Mesyanzhinov, V. V. (1999). The carboxy-terminal domain initiates trimerization of bacteriophage T4 fibritin. Biochemistry (Mosc), 64(7), 817-823.

Li, J., Ulitzky, L., Silberstein, E., Taylor, D. R., \& Viscidi, R. (2013). Immunogenicity and protection efficacy of monomeric and trimeric recombinant SARS coronavirus spike protein subunit vaccine candidates. Viral Immunol, 26(2), 126132. doi:10.1089/vim.2012.0076

Li, Q., Guan, X., Wu, P., Wang, X., Zhou, L., Tong, Y., . . Feng, Z. (2020). Early Transmission Dynamics in Wuhan, China, of Novel Coronavirus-Infected Pneumonia. N Engl J Med, 382(13), 1199-1207. doi:10.1056/NEJMoa2001316

Liu, C., \& Nelson, R. S. (2013). The cell biology of Tobacco mosaic virus replication and movement. Front Plant Sci, 4, 12. doi:10.3389/fpls.2013.00012

Long, Q. X., Liu, B. Z., Deng, H. J., Wu, G. C., Deng, K., Chen, Y. K., . . Huang, A. L. (2020). Antibody responses to SARS-CoV-2 in patients with COVID-19. Nat Med, 26(6), 845-848. doi:10.1038/s41591-020-0897-1

Lu, R., Zhao, X., Li, J., Niu, P., Yang, B., Wu, H., . . Tan, W. (2020). Genomic characterisation and epidemiology of 2019 novel coronavirus: implications for virus origins and receptor binding. Lancet, 395(10224), 565-574. doi:10.1016/S0140-6736(20)30251-8

Ma, H., Zeng, W., He, H., Zhao, D., Jiang, D., Zhou, P., . . Jin, T. (2020). Serum IgA, IgM, and IgG responses in COVID-19. Cell Mol Immunol, 17(7), 773-775. doi:10.1038/s41423-020-0474-z 
Meier, S., Guthe, S., Kiefhaber, T., \& Grzesiek, S. (2004). Foldon, the natural trimerization domain of T4 fibritin, dissociates into a monomeric A-state form containing a stable beta-hairpin: atomic details of trimer dissociation and local beta-hairpin stability from residual dipolar couplings. J Mol Biol, 344(4), 10511069. doi:10.1016/j.jmb.2004.09.079

Meyer, B., Drosten, C., \& Muller, M. A. (2014). Serological assays for emerging coronaviruses: challenges and pitfalls. Virus Res, 194, 175-183. doi:10.1016/j.virusres.2014.03.018

Nicol, T., Lefeuvre, C., Serri, O., Pivert, A., Joubaud, F., Dubee, V., . . . Le GuillouGuillemette, H. (2020). Assessment of SARS-CoV-2 serological tests for the diagnosis of COVID-19 through the evaluation of three immunoassays: Two automated immunoassays (Euroimmun and Abbott) and one rapid lateral flow immunoassay (NG Biotech). J Clin Virol, 129, 104511. doi:10.1016/j.jcv.2020.104511

Papanikolopoulou, K., Forge, V., Goeltz, P., \& Mitraki, A. (2004). Formation of highly stable chimeric trimers by fusion of an adenovirus fiber shaft fragment with the foldon domain of bacteriophage t4 fibritin. J Biol Chem, 279(10), 8991-8998. doi:10.1074/jbc.M311791200

Peng, G., Sun, D., Rajashankar, K. R., Qian, Z., Holmes, K. V., \& Li, F. (2011). Crystal structure of mouse coronavirus receptor-binding domain complexed with its murine receptor. Proc Natl Acad Sci U S A, 108(26), 10696-10701. doi:10.1073/pnas.1104306108

Premkumar, L., Segovia-Chumbez, B., Jadi, R., Martinez, D. R., Raut, R., Markmann, A., ... de Silva, A. M. (2020). The receptor binding domain of the viral spike protein is an immunodominant and highly specific target of antibodies in SARSCoV-2 patients. Sci Immunol, 5(48). doi:10.1126/sciimmunol.abc8413

Shereen, M. A., Khan, S., Kazmi, A., Bashir, N., \& Siddique, R. (2020). COVID-19 infection: Origin, transmission, and characteristics of human coronaviruses. $J A d v$ Res, 24, 91-98. doi:10.1016/j.jare.2020.03.005

Sissoeff, L., Mousli, M., England, P., \& Tuffereau, C. (2005). Stable trimerization of recombinant rabies virus glycoprotein ectodomain is required for interaction with the p75NTR receptor. J Gen Virol, 86(Pt 9), 2543-2552. doi:10.1099/vir.0.810630

Sivaraman, H., Er, S. Y., Choong, Y. K., Gavor, E., \& Sivaraman, J. (2021). Structural Basis of SARS-CoV-2- and SARS-CoV-Receptor Binding and Small-Molecule Blockers as Potential Therapeutics. Annu Rev Pharmacol Toxicol, 61, 465-493. doi:10.1146/annurev-pharmtox-061220-093932

Sterlin, D., Mathian, A., Miyara, M., Mohr, A., Anna, F., Claer, L., . . Gorochov, G. (2021). IgA dominates the early neutralizing antibody response to SARS-CoV-2. Sci Transl Med, 13(577). doi:10.1126/scitranslmed.abd2223

Sun, Z. F., \& Meng, X. J. (2004). Antigenic cross-reactivity between the nucleocapsid protein of severe acute respiratory syndrome (SARS) coronavirus and polyclonal antisera of antigenic group I animal coronaviruses: implication for SARS 
diagnosis. J Clin Microbiol, 42(5), 2351-2352. doi:10.1128/jcm.42.5.23512352.2004

Tai, W., He, L., Zhang, X., Pu, J., Voronin, D., Jiang, S., . . Du, L. (2020).

Characterization of the receptor-binding domain (RBD) of 2019 novel coronavirus: implication for development of RBD protein as a viral attachment inhibitor and vaccine. Cell Mol Immunol, 17(6), 613-620. doi:10.1038/s41423020-0400-4

Tai, W., Zhang, X., He, Y., Jiang, S., \& Du, L. (2020). Identification of SARS-CoV RBD-targeting monoclonal antibodies with cross-reactive or neutralizing activity against SARS-CoV-2. Antiviral Res, 179, 104820. doi:10.1016/j.antiviral.2020.104820

Tai, W., Zhao, G., Sun, S., Guo, Y., Wang, Y., Tao, X., . . Z Zhou, Y. (2016). A recombinant receptor-binding domain of MERS-CoV in trimeric form protects human dipeptidyl peptidase 4 (hDPP4) transgenic mice from MERS-CoV infection. Virology, 499, 375-382. doi:10.1016/j.virol.2016.10.005

Tang, T., Bidon, M., Jaimes, J. A., Whittaker, G. R., \& Daniel, S. (2020). Coronavirus membrane fusion mechanism offers a potential target for antiviral development. Antiviral Res, 178, 104792. doi:10.1016/j.antiviral.2020.104792

Timiryasova, T. M., Bonaparte, M. I., Luo, P., Zedar, R., Hu, B. T., \& Hildreth, S. W. (2013). Optimization and validation of a plaque reduction neutralization test for the detection of neutralizing antibodies to four serotypes of dengue virus used in support of dengue vaccine development. Am J Trop Med Hyg, 88(5), 962-970. doi:10.4269/ajtmh.12-0461

Toptan, T., Hoehl, S., Westhaus, S., Bojkova, D., Berger, A., Rotter, B., . . W Widera, M. (2020). Optimized qRT-PCR Approach for the Detection of Intra- and ExtraCellular SARS-CoV-2 RNAs. Int J Mol Sci, 21(12). doi:10.3390/ijms21124396

Tso, F. Y., Lidenge, S. J., Pena, P. B., Clegg, A. A., Ngowi, J. R., Mwaiselage, J., . . Wood, C. (2021). High prevalence of pre-existing serological cross-reactivity against severe acute respiratory syndrome coronavirus-2 (SARS-CoV-2) in subSaharan Africa. Int J Infect Dis, 102, 577-583. doi:10.1016/j.ijid.2020.10.104

Walls, A. C., Park, Y. J., Tortorici, M. A., Wall, A., McGuire, A. T., \& Veesler, D. (2020). Structure, Function, and Antigenicity of the SARS-CoV-2 Spike Glycoprotein. Cell, 181(2), 281-292 e286. doi:10.1016/j.cell.2020.02.058

Wang, Q., Zhang, Y., Wu, L., Niu, S., Song, C., Zhang, Z., . . Qi, J. (2020). Structural and Functional Basis of SARS-CoV-2 Entry by Using Human ACE2. Cell, 181(4), 894-904 e899. doi:10.1016/j.cell.2020.03.045

Welsh, J. P., Lu, Y., He, X. S., Greenberg, H. B., \& Swartz, J. R. (2012). Cell-free production of trimeric influenza hemagglutinin head domain proteins as vaccine antigens. Biotechnol Bioeng, 109(12), 2962-2969. doi:10.1002/bit.24581

WHO. (2021). World Health Organization Coronavirus Disease (COVID-19) Dashboard. Retrieved from https://covid19.who.int/

Wrapp, D., Wang, N., Corbett, K. S., Goldsmith, J. A., Hsieh, C. L., Abiona, O., . . . McLellan, J. S. (2020). Cryo-EM structure of the 2019-nCoV spike in the 
prefusion conformation. Science, 367(6483), 1260-1263.

doi:10.1126/science.abb2507

Yan, R., Zhang, Y., Li, Y., Xia, L., Guo, Y., \& Zhou, Q. (2020). Structural basis for the recognition of SARS-CoV-2 by full-length human ACE2. Science, 367(6485), 1444-1448. doi:10.1126/science.abb2762

Younes, N., Al-Sadeq, D. W., Al-Jighefee, H., Younes, S., Al-Jamal, O., Daas, H. I., . . . Nasrallah, G. K. (2020). Challenges in Laboratory Diagnosis of the Novel Coronavirus SARS-CoV-2. Viruses, 12(6). doi:10.3390/v12060582

Yu, F., Xiang, R., Deng, X., Wang, L., Yu, Z., Tian, S., . . Jiang, S. (2020). Receptorbinding domain-specific human neutralizing monoclonal antibodies against SARS-CoV and SARS-CoV-2. Signal Transduct Target Ther, 5(1), 212. doi:10.1038/s41392-020-00318-0

Zhang, Y., Wada, J., Yasuhara, A., Iseda, I., Eguchi, J., Fukui, K., . . Makino, H. (2007). The role for HNF-1beta-targeted collectrin in maintenance of primary cilia and cell polarity in collecting duct cells. PLoS One, 2(5), e414. doi:10.1371/journal.pone.0000414

Zhou, P., Yang, X. L., Wang, X. G., Hu, B., Zhang, L., Zhang, W., . . Shi, Z. L. (2020a). Addendum: A pneumonia outbreak associated with a new coronavirus of probable bat origin. Nature, 588(7836), E6. doi:10.1038/s41586-020-2951-Z

Zhou, P., Yang, X. L., Wang, X. G., Hu, B., Zhang, L., Zhang, W., . . . Shi, Z. L. (2020b). A pneumonia outbreak associated with a new coronavirus of probable bat origin. Nature, 579(7798), 270-273. doi:10.1038/s41586-020-2012-7

Zost, S. J., Gilchuk, P., Case, J. B., Binshtein, E., Chen, R. E., Nkolola, J. P., . . Crowe, J. E., Jr. (2020). Potently neutralizing and protective human antibodies against SARS-CoV-2. Nature, 584(7821), 443-449. doi:10.1038/s41586-020-2548-6 
VITA

Joey Breckenridge, Jr. received his Bachelor of Science in Bioengineering from the University of Louisville in 2021. While a student, he was a Speed School of Engineering student ambassador and a peer mentor for the annual Brown Forman Engineering Academy. Also, he served as an executive board member of the University of Louisville chapter of the National Society of Black Engineers and was a member of the Biomedical Engineering Society. Joey worked as an undergraduate researcher and bioengineering coop in the Center for Predictive Medicine under the supervision of Dr. Joshua Fuqua. He researched the production and testing of Griffithsin tandemers for use in binding HIV particles, and the production and testing of bactericidal proteins, called pyocins, for use in preventing Pseudomonas Aeruginosa infection. A publication is under development for his work on pyocins. In his research with Dr. Fuqua, he learned a number of wet-lab and protein production techniques including bacterial cell culture, plant-based protein extraction, fast protein liquid chromatography, polyacrylamide gel electrophoresis, and ELISA. Currently, Joey is completing his Master of Engineering in Bioengineering at the University of Louisville in the laboratory of Dr. Joshua Fuqua. Joey has been accepted to the University of Cincinnati/Cincinnati Children's Hospital Medical Center Immunology PhD Program and will be attending July of 2021. 